\title{
Tibetan sheep have a high capacity to absorb and to regulate metabolism of SCFA in the rumen epithelium to adapt to low energy intake
}

\author{
Xiaoping Jing ${ }^{1,2}$, Wenji Wang ${ }^{1}$, Allan Degen ${ }^{3}$, Yamin Guo ${ }^{4}$, Jingpeng Kang ${ }^{4}$, Peipei Liu ${ }^{1}$, Luming Ding ${ }^{1}$, \\ Zhanhuan Shang ${ }^{1}$, Veerle Fievez ${ }^{2}$, Jianwei Zhou ${ }^{4 *}$ and Ruijun Long ${ }^{1 *}$ \\ ${ }^{1}$ State Key Laboratory of Grassland and Agro-Ecosystems, International Centre for Tibetan Plateau Ecosystem Management, \\ School of Life Sciences, Lanzhou University, Lanzhou 730000, People's Republic of China \\ ${ }^{2}$ Laboratory for Animal Nutrition and Animal Product Quality, Department of Animal Sciences and Aquatic Ecology, Faculty of \\ Bioscience Engineering, Ghent University, 9000 Ghent, Belgium \\ ${ }^{3}$ Desert Animal Adaptations and Husbandry, Wyler Department of Dryland Agriculture, Blaustein Institutes for Desert \\ Research, Ben-Gurion University of Negev, Beer Sheva 8410500, Israel \\ ${ }^{4}$ State Key Laboratory of Grassland and Agro-Ecosystems, College of Pastoral Agriculture Science and Technology, \\ Lanzhou University, Lanzhou 730000, People's Republic of China \\ (Submitted 11 September 2019 - Final revision received 1 December 2019 - Accepted 2 December 2019)
}

\section{Abstract}

The nutritional intake of Tibetan sheep on the harsh Qinghai-Tibetan Plateau is often under maintenance requirements, especially during the long, cold winter. However, they have adapted well and even thrive under these conditions. The aim of the present study was to gain insight into how the rumen epithelium of Tibetan sheep has adapted to the consumption of low-energy-level diets. For this purpose, we compared Tibetan and small-tailed Han sheep ( $n 24$ of each breed, all wethers and 1.5 years of age), which were divided randomly into one of four groups and offered ad libitum diets of different digestible energy (DE) densities: 8.21, 9.33, 10.45 and 11.57 MJ DE/kg DM. The Tibetan sheep had higher rumen concentrations of total SCFA, acetate, butyrate and iso-acids but lower concentrations of propionate than small-tailed Han sheep. The Tibetan sheep had higher absorption capability of SCFA due to the greater absorption surface area and higher mRNA expression of the SCFA absorption relative genes than small-tailed Han sheep. For the metabolism of SCFA in the rumen epithelium, the small-tailed Han sheep showed higher utilisation of the ketogenesis pathway than Tibetan sheep; however, Tibetan sheep had greater regulation capacity in SCFA metabolism pathways. These differences between breeds allowed the Tibetan sheep to have greater capability of absorbing SCFA and better capacity to regulate the metabolism of SCFA, which would allow them to cope with low energy intake better than small-tailed Han sheep.

Key words: Tibetan sheep: Small-tailed Han sheep: Dietary energy level: SCFA absorption: SCFA metabolism

Tibetan sheep (Ovis aries) play a vital role in the livelihoods of Tibetan pastoralists and an important role in the QinghaiTibetan Plateau (QTP) ecosystem. They provide meat, milk, wool, fuel and leather to local herdsman in this region and play an influential role in the maintenance of Tibetan culture. Tibetan sheep are especially important in the western region of Tibet, where they comprise up to $96 \%$ of the livestock in some areas ${ }^{(1)}$. Under traditional management, Tibetan sheep graze on rangeland all year round and are dependent on the native grassland to survive. In addition, due to the extremely harsh environment of the QTP, the growing period of herbage is short (90-120 d) and the biomass and nutrients of the forage are often well below requirements in the winter ${ }^{(2)}$. Consequently, during the long, cold season, they can lose $40 \%$ of their body weight ${ }^{(3)}$.

However, the sheep have adapted well and even have thrived under these harsh conditions for thousands of years. It has been reported that Tibetan sheep produce a higher yield of SCFA than low-altitude sheep breeds ${ }^{(4)}$. The SCFA are produced in the rumen by microbial metabolism during carbohydrate fermentation, and 50-85\% are absorbed directly across the rumen epithelium and, subsequently, serve as the principle energy source for ruminants ${ }^{(5)}$. Furthermore, SCFA are the

Abbreviations: ACAT, acetoacetyl-CoA acetyl transferase; AE2, anion exchanger 2; DRA, down-regulated-in-adenoma; FFAR, free fatty acid receptor; HMGCR, 3-hydroxy, 3-methylglutaryl CoA reductase; HMGCS, 3-hydroxy, 3-methylglutaryl CoA synthase; MCT, monocarboxylate transporter; Na ${ }^{+} \mathrm{K}^{+}$-ATPase, Na/K ATPase; NBC1, $\mathrm{Na}^{+} / \mathrm{HCO}_{3}{ }^{-}$cotransporter 1; NHE, Na/H antiporter; PAT1, putative anion transporter 1; QTP, Qinghai-Tibetan Plateau; SREBP-2, sterol regulatory element-binding protein $2 ; \nu^{+}$-ATPase, vacuolar-type ATPase. 
primary energy source for the functions of the ruminal epithelium $^{(6)}$ and are preferred by ruminal epithelial cells ${ }^{(7)}$. The absorption of SCFA by ruminal epithelium is highly dependent on the papillae surface area and the availability of transport protein expressions ${ }^{(8,9)}$. In addition, the development and renewal of rumen epithelium depend on adequate nutrient intake, and the intake of energy-rich diets promotes the growth of rumen tissues and the increase in SCFA production ${ }^{(10,11)}$.

Small-tailed Han sheep (Ovis aries), a popular breed raised in the northern plains and hilly regions of China, were introduced to the agricultural, semi-agricultural and pastoral farming regions of QTP in the 1980s because of their high prolificacy and nonseasonal ovulatory activity ${ }^{(12)}$. They are generally raised in feed-lots under intensive management and graze natural pasture only in summer. It was reported that Tibetan sheep were better able to cope with low energy intake than small-tailed Han sheep due, at least in part, to lower maintenance energy requirements and higher nutrient digestibilities ${ }^{(13)}$. However, SCFA production and underlying physiological, biochemical and histological adaptation mechanisms of the rumen epithelium in Tibetan sheep are unknown and, consequently, are the subject of the present study. Based on their different backgrounds and previous comparative studies, we hypothesised that Tibetan and small-tailed Han sheep would differ in their ruminal SCFA production and absorption mechanisms and predicted that the differences would allow Tibetan sheep to cope better with low energy intake than small-tailed Han sheep. To test this prediction, we formulated four different energy level diets and determined growth performance, ruminal SCFA production, ruminal papillae morphology and the relative gene expressions of SCFA absorption, metabolism and regulation in ruminal epithelium in Tibetan and small-tailed Han sheep. Low energy levels were included in the treatments as the Tibetan sheep are often faced with low intakes.

\section{Materials and methods}

All procedures in this research were approved by the Institutional Animal Care and Use Committee of Lanzhou University. The study was done during October and December 2016, at the Yak Research Station of Lanzhou University, Tianzhu Tibetan Autonomous County, Gansu Province, north-eastern QTP, China. Average air temperature during the study was $6^{\circ} \mathrm{C}$, and relative humidity was $76 \%$.

\section{Animals and experimental design}

The experimental design was described previously ${ }^{(13)}$. Briefly, twenty-four Tibetan sheep (body weight $=48.5($ sD 1.89$) \mathrm{kg}$ ) and twenty-four small-tailed Han sheep (body weight = $49 \cdot 2(\mathrm{sD} 2 \cdot 21) \mathrm{kg}$ ), all wethers aged 1.5 years, were maintained under a three-sided roofed shelter. Sheep of each breed were divided randomly into one of four groups (six sheep/group per breed) and received a diet yielding a digestible energy density of $8 \cdot 21,9 \cdot 33,10.45$ or $11.57 \mathrm{MJ} / \mathrm{kg} \mathrm{DM}$ (online Supplementary Table S1). The diets all contained about $70 \mathrm{~g} / \mathrm{kg}$ crude protein, which is similar to the average crude protein content in forage of the QTP during the cold season ${ }^{(14)}$. The sheep were penned individually in $1.5 \times 2.5 \mathrm{~m}$ pens with a sand floor that was equipped with a water tank and a feed trough. They were allowed $14 \mathrm{~d}$ to adapt to the conditions, which was followed by a 42 -d feeding period in which diets were offered in two equal portions at 08.00 and 18.00 hours, and feed intake was measured.

\section{Data collection and sampling procedures}

Sheep were weighed every 2 weeks before morning feeding, and average daily gain was calculated. Following $42 \mathrm{~d}$ of feed intake and $7 \mathrm{~d}$ of metabolism trials, all sheep were slaughtered humanely $2-3 \mathrm{~h}$ after morning feeding ${ }^{(15)}$. Rumen fluid of $25 \mathrm{ml}$ was collected from each sheep immediately after slaughter and filtered through four layers of cheesecloth ${ }^{(16)}$. The $\mathrm{pH}$ was measured immediately using a $\mathrm{pH}$ electrode meter (Sartorius PB-10, Sartorius Scientific Instruments (Beijing) Co. Ltd), snapfrozen in liquid $\mathrm{N}_{2}$ and then stored at $-80^{\circ} \mathrm{C}$ for analyses of SCFA and ammonia. Samples of rumen tissue from the dorsal and ventral sacs $(2 \times 2 \mathrm{~cm}$, three pieces $)$ were collected from each sheep, and the number of papillae in $1 \mathrm{~cm}^{2}$ was counted. The tissues were fixed in $4 \%$ ( $\mathrm{vol} / \mathrm{vol})$ paraformaldehyde solution for rumen morphological examination and immunohistochemistry analysis. Rumen epithelium samples of the dorsal and ventral sacs were rinsed repeatedly with physiological saline, cut into small pieces, placed into $1.5 \mathrm{ml}$ tubes (Eppendorf, GCS), snap-frozen in liquid $\mathrm{N}_{2}$ and stored at $-80^{\circ}$ C for RNA extraction for mRNA expression determination.

\section{Measurements}

SCFA and ammonia-nitrogen analysis. The concentration of SCFA (acetic, propionic, iso-butyric, butyric, iso-valeric and valeric) was determined by GC (SP-3420A, Beifenrili Analyser Associates). Rumen fluid samples were thawed and centrifuged at $20000 \boldsymbol{g}$ for $10 \mathrm{~min}^{(16)}$ and then injected into an AT-FFAP capillary column $(30 \mathrm{~m} \times 0.32 \mathrm{~mm}$ internal diameter $\times 0.5 \mu \mathrm{m}$ film thickness, Varian Inc.). Samples were run at a split vent flow of $40 \mathrm{ml} / \mathrm{min}$, air flow of $450 \mathrm{ml} / \mathrm{min}$, make-up gas flow of $35 \mathrm{ml} / \mathrm{min}$, with a capillary column temperature of $90^{\circ} \mathrm{C}$, increased to $120^{\circ} \mathrm{C}$ at a rate of $10^{\circ} \mathrm{C} / \mathrm{min}$ and held for $3 \mathrm{~min}$, and then increased to $180^{\circ} \mathrm{C}$ at the same rate and held for $5 \mathrm{~min}$. The injection port temperature was $220^{\circ} \mathrm{C}$, and the flame ionisation detector temperature was $250^{\circ} \mathrm{C}$. The concentration of ammonia-N was analysed by colorimetry using a spectrophotometer (U-2900) according to Hristov et al. ${ }^{(16)}$.

Rumen papillae morphology. The fixed rumen dorsal and ventral sac tissue samples were rinsed in water, dehydrated with a series of absolute ethanol, cleared with xylene and saturated with and embedded in paraffin ${ }^{(17)}$. The blocks were cut into $5 \mu \mathrm{m}$ sections using a rotary microtome (RM2235, Leica), and the sections (four slices of each sample) were stained by haematoxylin-eosin. Ten images per slice in random fields were examined microscopically (Olympus DP2-BSW). Ruminal papillae height and width, and epithelium, stratum corneum and lamina propria thicknesses in each image were determined by Image-Pro Plus 6.0 software (Media Cybernetics Inc.) and reported as the mean of representative papillae for each sheep. 
Ruminal papillae length and width were measured at $4 \times$ objective lens, and ruminal mucosa and stratum corneum thicknesses were measured at $20 \times$ objective lens according to Diaz et al. (online Supplementary Fig. S1) ${ }^{(18)}$. The surface area of papillae was calculated as length $\times$ width $\times 2^{(10)}$.

\section{RNA extraction and mRNA expression determination.}

Rumen epithelium samples of the dorsal and ventral sacs were ground in a sterile environment using a sterilised mortar with liquid $\mathrm{N}_{2}$. Total RNA was then isolated using Trizol reagent (Invitrogen, Life Technologies). The quality of RNA was monitored spectrophotometrically at 260 and $280 \mathrm{~nm}$ and also checked by $1.0 \%$ agarose gel electrophoresis. One $\mu$ g of total RNA was used for reverse transcription reaction to generate cDNA by a Prime Script ${ }^{\circledR}$ RT Reagent Kit (Takara Biotechnology Co. Ltd) according to the manufacturer's protocol. Following reverse transcription, cDNA quantity was determined and standardised to the required concentration for quantitative real-time reverse transcription PCR analysis. The cDNA was amplified by real-time PCR using an SYBR Green real-time PCR master mix kit (Takara Biotechnology Co. Ltd) with the Agilent StrataGene Mx3000P (Agilent Technologies Inc.) in a total volume of $20 \mu$ l, containing 10.0 $\mu \mathrm{l}$ SYBR Premix Ex Taq II, $0 \cdot 8 \mu \mathrm{l}$ forward primers $(10 \mu \mathrm{m} / \mathrm{l})$ and $0.8 \mu \mathrm{l}$ reverse primers $(10 \mu \mathrm{m} / \mathrm{l}), 0.4 \mu \mathrm{l}$ ROX Reference Dye II $(50 \times), 2 \mu \mathrm{l}$ cDNA and $6.0 \mu \mathrm{l}$ nuclease-free $\mathrm{H}_{2} \mathrm{O}$. The PCR plate was incubated at $95^{\circ} \mathrm{C}$ for $30 \mathrm{~s}$, followed by 39 cycles at $95^{\circ} \mathrm{C}$ for $5 \mathrm{~s}$, annealing at a temperature of each primer for $34 \mathrm{~s}$ followed by amplicon dissociation $\left(95^{\circ} \mathrm{C}\right.$ for $15 \mathrm{~s}, 60^{\circ} \mathrm{C}$ for $60 \mathrm{~s}$ and $95^{\circ} \mathrm{C}$ for $15 \mathrm{~s})$. The melting peaks of all samples were determined routinely by melting curve analysis to ascertain that only the expected products had been generated. The FFAR2 and FFAR3 (free fatty acid receptor, isoform 2 and 3); MCT1, MCT2 and MCT4 (monocarboxylate cotransporter isoforms 1, 2 and 4); NHE1 and $N H E 3(\mathrm{Na} / \mathrm{H}$ antiporter, isoform 1 and 3); $\mathrm{Na}^{+} / \mathrm{K}^{+}$-ATPase (Na/K ATPase); $\nu H^{+}$ATPase (vacuolar-type ATPase); DRA (down-regulated-inadenoma); $N B C 1\left(\mathrm{Na}^{+} / \mathrm{HCO}_{3}{ }^{-}\right.$cotransporter 1); PAT1 (putative anion transporter 1); $A E 2$ (anion exchanger 2); $A C A T 1$ and $A C A T 2$ (acetoacetyl-CoA acetyl transferase, isoform 1 and 2); HMGCS1 and HMGCS2 (3-hydroxy, 3-methylglutaryl CoA synthase, isoform 1 and 2); PPAR- $\alpha$; HMGCR (3-hydroxy, 3-methylglutaryl CoA reductase); SREBP-2 (sterol regulatory elementbinding protein 2) and $\beta$-actin primers were designed using Primer Premier 5.0 (Premier Biosoft International) (online Supplementary Table S2). $\beta$-Actin was used as a housekeeping gene. The oligonucleotides were synthesised by Takara Biotechnology Co. Ltd. Relative gene mRNA expression levels are presented as $2^{-\Delta \Delta \mathrm{Ct}(19)}$.

Immunohistochemistry analysis. The paraffin-embedded tissues of the ruminal dorsal and ventral sacs were sectioned at $5 \mu \mathrm{m}$ using a rotary microtome (RM2235) and processed for immunohistochemistry analysis of MCT1, MCT2, MCT4, NHE1, NHE3, $\mathrm{Na}^{+} / \mathrm{K}^{+}$-ATPase, $\nu H^{+}$-ATPase and AE2. The sections were incubated with the primary antibody against $M C T 1$ (1:100), MCT2 (1:500), MCT4 (1:200), NHE1 (1:100), NHE3 (1:100), $\mathrm{Na}^{+} / \mathrm{K}^{+}$-ATPase (1:100), $\nu H^{+}$-ATPase (1:300) and AE2 (1:100) overnight at $4{ }^{\circ} \mathrm{C}$ (all primary antibodies were from Santa Cruz
Biotechnology, Inc.), and then, the sections were washed and incubated with a biotinylated secondary antibody (ZSGB Biotechnology Co. Ltd). Immunostaining was visualised by the peroxidase method with diaminobenzidine as the chromogen. Cells were observed and photographed under light microscopy (20x objective lens) and those with brown granules were considered immunoreactions-positive signals ${ }^{(20)}$.

\section{Statistical analysis}

The mixed model of the SAS statistical package (SAS version 9.4, SAS Inst. Inc.) was used to analyse the data. There were two levels of error in the model: (1) the variation between breeds was compared with the variation among animals of the same breed; and (2) the variation among diets was compared with the residual variation within animals. Polynomial contrasts were used to determine the effect of dietary energy level and the interaction between breeds. Comparison between breeds at the same dietary energy level was made using $t$ tests when there was a significant interaction between dietary energy level and breed ${ }^{(21)}$. Differences were considered significant at $P<0.05$, and with a tendency to differ at $P>0 \cdot 05$ and $<0 \cdot 10$.

\section{Results}

\section{Daily intake and body weight change}

Daily intakes and growth performance of the sheep have been described previously ${ }^{(13)}$. There was no difference in daily DM and crude protein intakes among dietary treatments $(P>0.05)$ and between Tibetan and small-tailed Han sheep $(P>0.05)$. However, digestible energy intake, by design, increased linearly $(P<0.001)$ as dietary energy level increased, but was similar between breeds $(P>0 \cdot 05)$. The neutral-detergent fibre and acid-detergent fibre intakes decreased linearly with an increase in dietary energy level $(P<0 \cdot 001)$, but did not differ between breeds $(P>0 \cdot 05)$. Average daily gain was significantly greater in Tibetan than small-tailed Han sheep across treatments (linear dietary energy level $\times$ breed, $P=0.003$ ) and increased linearly $(P<0.001)$ in both breeds with an increase in dietary energy level.

\section{Ruminal SCFA production}

Rumen concentrations of total SCFA and butyrate were higher in Tibetan than in small-tailed Han sheep $(P<0.001)$ and increased linearly with an increase in dietary energy level $(P<0.001$, Table 1$)$. The concentration of propionate also increased linearly with an increase in dietary energy level $(P<0.001)$, but was higher in small-tailed Han than in Tibetan sheep $(P=0.005)$, whereas the concentration of acetate decreased linearly as the dietary energy level increased $(P<0.001)$ and was higher in Tibetan than in small-tailed Han sheep $(P=0.002)$. The concentration of valerate increased linearly as the dietary energy level increased $(P<0 \cdot 001)$, but there was no difference between breeds $(P>0.05)$, and the concentration of iso-acids also increased linearly as the dietary energy level increased $(P<0 \cdot 001)$, but were higher in Tibetan 
$\mathrm{X}$. Jing et al.

Table 1. SCFA production in the rumen of Tibetan $(T)$ and small-tailed Han $(H)$ sheep offered diets of different energy levels (Mean values with their pooled standard errors)

\begin{tabular}{|c|c|c|c|c|c|c|c|c|c|c|}
\hline \multirow[b]{2}{*}{ Items } & \multirow[b]{2}{*}{ Breed } & \multicolumn{4}{|c|}{ Dietary energy level $(\mathrm{MJ} / \mathrm{kg} \mathrm{DM})$} & \multirow[b]{2}{*}{ SEM } & \multicolumn{4}{|c|}{$P \dagger$} \\
\hline & & $8 \cdot 21$ & $9 \cdot 33$ & $10 \cdot 45$ & 11.57 & & Breed & E-L & $E-Q$ & $\mathrm{E}-\mathrm{C}$ \\
\hline \multirow[t]{2}{*}{$\mathrm{pH}$} & $\mathrm{T}$ & 6.63 & 6.58 & 6.40 & $6 \cdot 15$ & \multirow[t]{2}{*}{0.111} & \multirow[t]{2}{*}{0.047} & $<0.001$ & 0.893 & 0.671 \\
\hline & $\mathrm{H}$ & 6.92 & 6.59 & 6.53 & $6 \cdot 37$ & & & $0.879 \ddagger$ & $0.246 \ddagger$ & $0.547 \ddagger$ \\
\hline \multirow[t]{2}{*}{ Total SCFA $(\mathrm{mmol} / \mathrm{l})$} & $\mathrm{T}$ & 76.9 & $85 \cdot 7$ & 92.1 & $99 \cdot 3$ & \multirow[t]{2}{*}{$6 \cdot 79$} & \multirow[t]{2}{*}{0.009} & 0.002 & 0.647 & 0.936 \\
\hline & $\mathrm{H}$ & $62 \cdot 3$ & $73 \cdot 2$ & $80 \cdot 3$ & $84 \cdot 1$ & & & $0.979 \ddagger$ & $0.769 \ddagger$ & $0.952 \ddagger$ \\
\hline \multirow[t]{2}{*}{ Acetate $(\mathrm{mol} / 100 \mathrm{~mol})$} & $\mathrm{T}$ & $71 \cdot 1$ & $68 \cdot 7$ & $66 \cdot 7$ & $65 \cdot 6$ & \multirow[t]{2}{*}{0.998} & \multirow[t]{2}{*}{0.002} & $<0.001$ & 0.324 & 0.905 \\
\hline & $\mathrm{H}$ & $68 \cdot 2$ & 65.9 & $64 \cdot 3$ & 63.6 & & & $0.638 \ddagger$ & $0.908 \ddagger$ & $0.945 \ddagger$ \\
\hline \multirow[t]{2}{*}{ Propionate $(\mathrm{mol} / 100 \mathrm{~mol})$} & $\mathrm{T}$ & $17 \cdot 2$ & 18.9 & $19 \cdot 1$ & $20 \cdot 8$ & \multirow[t]{2}{*}{0.626} & \multirow[t]{2}{*}{0.005} & $<0.001$ & 0.617 & 0.883 \\
\hline & $\mathrm{H}$ & 18.5 & $19 \cdot 7$ & 21.5 & 21.7 & & & $0.914 \ddagger$ & $0.626 \ddagger$ & $0.190 \ddagger$ \\
\hline \multirow[t]{2}{*}{ Butyrate $(\mathrm{mol} / 100 \mathrm{~mol})$} & $\mathrm{T}$ & 8.23 & 9.58 & 11.3 & $12 \cdot 2$ & \multirow[t]{2}{*}{0.526} & \multirow[t]{2}{*}{0.016} & $<0.001$ & 0.565 & 0.753 \\
\hline & $\mathrm{H}$ & 8.04 & 9.08 & 9.88 & 10.4 & & & $0.099 \ddagger$ & $0.943 \ddagger$ & $0.753 \ddagger$ \\
\hline \multirow[t]{2}{*}{ Valerate $(\mathrm{mol} / 100 \mathrm{~mol})$} & $\mathrm{T}$ & 0.693 & 0.853 & 0.879 & 0.949 & \multirow[t]{2}{*}{0.0520} & \multirow[t]{2}{*}{0.211} & $<0.001$ & 0.687 & 0.651 \\
\hline & $\mathrm{H}$ & 0.789 & 0.842 & 0.924 & 1.008 & & & $0.872 \ddagger$ & $0.419 \ddagger$ & $0.538 \ddagger$ \\
\hline \multirow[t]{2}{*}{ Iso-acids (mol/100 mol) } & $\mathrm{T}$ & 2.02 & $2 \cdot 40$ & $2 \cdot 68$ & 2.92 & \multirow[t]{2}{*}{0.103} & \multirow[t]{2}{*}{$<0.001$} & $<0.001$ & 0.452 & 0.599 \\
\hline & $\mathrm{H}$ & $1 \cdot 81$ & 1.98 & $2 \cdot 32$ & $2 \cdot 41$ & & & $0.228 \ddagger$ & $0.870 \ddagger$ & $0.451 \ddagger$ \\
\hline
\end{tabular}

* Digestible energy on a DM basis.

$\dagger \mathrm{E}-\mathrm{L}=$ linear effect of dietary energy level; $\mathrm{E}-\mathrm{Q}=$ quadratic effect of dietary energy level; $\mathrm{E}-\mathrm{C}=$ cubic effect of dietary energy level.

$\ddagger P$ value for the interaction of dietary energy level effect with species.

(a)

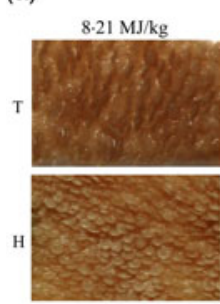

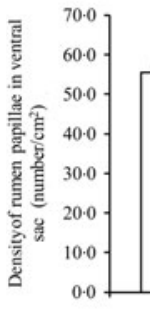

Rumen dorsal sac
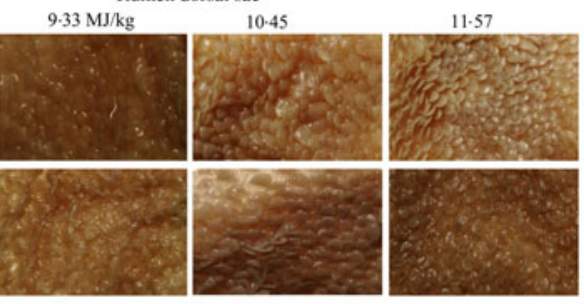

Dietary energy level $(\mathrm{MJ} / \mathrm{kg})$ (b)
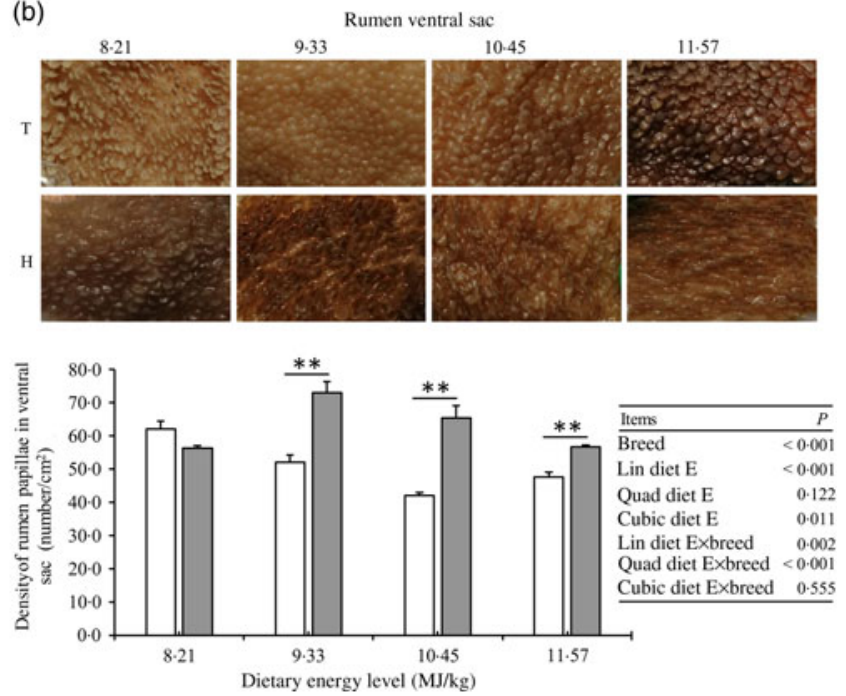

Fig. 1. Papillae density in the rumen of Tibetan $(T)$ and small-tailed Han $(H)$ sheep offered diets of different energy $(E)$ levels. The dietary energy levels are digestible energy on a DM basis. ${ }^{*} P<0.05$, ${ }^{\star *} P<0.01$. $\square$, Small-tailed Han sheep; $\square$, Tibetan sheep. Lin, linear; Quad, quadratic.

than in small-tailed Han sheep $(P<0.001)$. The $\mathrm{pH}$ values decreased linearly with an increase in dietary energy level and were lower in Tibetan than in small-tailed Han sheep.

\section{Rumen papillae morphology development}

The papillae densities in both the dorsal and ventral sacs of the rumen were higher in Tibetan than in small-tailed Han sheep $(P<0.01)$ when offered the three higher energy levels (Fig. 1) and increased linearly $(P<0 \cdot 001)$ in the dorsal sac but decreased linearly in the ventral $\operatorname{sac}(P<0.001)$ as the dietary energy increased.

In the dorsal sac of the rumen, the ruminal papillae height and surface area were greater in Tibetan than small-tailed Han sheep (linear dietary energy level $\times$ breed, $P<0 \cdot 001$ ) at the two highest energy levels (Table 2), while the width was greater in smalltailed Han than in Tibetan sheep at the lowest energy level, but greater in Tibetan than in small-tailed Han sheep at the highest energy level (linear dietary energy level $\times$ breed, $P<0 \cdot 001$ ). The ruminal papillae epithelium was thicker in Tibetan than in small-tailed Han sheep at the energy level of $9.33 \mathrm{MJ} / \mathrm{kg}$ (cubic dietary energy level $\times$ breed, $P<0.05$ ), and the stratum corneum of the ruminal papillae was thicker in Tibetan than in small-tailed Han sheep $(P=0.007)$ and increased linearly in both breeds as the dietary energy level increased $(P<0.001)$. However, the lamina propria thickness of the ruminal papillae decreased linearly with an increase in dietary energy level $(P<0 \cdot 001)$ and was thicker in small-tailed Han than in Tibetan sheep $(P=0.038)$. Representative micrographs are presented in online Supplementary Fig. S2.

The papillae surface area and the papillae height in the ventral sac of the rumen were greater in Tibetan than small-tailed Han sheep (linear dietary energy level $\times$ breed, $P<0.001$ ) at 
Table 2. Morphological development of rumen papillae in the dorsal sac of the rumen in Tibetan $(T)$ and small-tailed Han $(H)$ sheep offered diets of different energy levels

(Mean values with their pooled standard errors)

\begin{tabular}{|c|c|c|c|c|c|c|c|c|c|c|}
\hline \multirow[b]{2}{*}{ Items } & \multirow[b]{2}{*}{ Breed } & \multicolumn{4}{|c|}{ Dietary energy level $(\mathrm{MJ} / \mathrm{kg} \mathrm{DM})$} & \multirow[b]{2}{*}{ SEM } & \multicolumn{4}{|c|}{$P \dagger$} \\
\hline & & $8 \cdot 21$ & $9 \cdot 33$ & $10 \cdot 45$ & 11.57 & & Breed & E-L & $E-Q$ & $\mathrm{E}-\mathrm{C}$ \\
\hline \multirow[t]{2}{*}{ Papilla surface area $\left(\mathrm{mm}^{2}\right)$} & $\mathrm{T}$ & 0.503 & 0.596 & $0 \cdot 650^{\mathrm{a}}$ & $0.724^{a}$ & 0.0475 & 0.001 & 0.932 & 0.811 & 0.357 \\
\hline & $\mathrm{H}$ & 0.590 & 0.568 & $0.426^{b}$ & $0.390^{\mathrm{b}}$ & & & $<0.001 \ddagger$ & $0.978 \ddagger$ & $0.585 \ddagger$ \\
\hline \multirow[t]{2}{*}{ Papilla height $(\mathrm{mm})$} & $\mathrm{T}$ & 1.23 & 1.40 & $1.59^{\mathrm{a}}$ & $1.39^{\mathrm{a}}$ & 0.097 & $<0.001$ & 0.137 & 0.029 & 0.709 \\
\hline & $\mathrm{H}$ & 1.26 & 1.36 & $1.01^{\mathrm{b}}$ & $0.84^{b}$ & & & $0.001 \ddagger$ & $0.662 \ddagger$ & $0.102 \ddagger$ \\
\hline \multirow[t]{2}{*}{ Papilla width (mm) } & $\mathrm{T}$ & $0.204^{b}$ & 0.213 & 0.206 & $0.261^{a}$ & 0.0071 & 0.931 & 0.002 & $<0.001$ & 0.134 \\
\hline & $\mathrm{H}$ & $0.233^{a}$ & 0.210 & 0.212 & $0.230^{b}$ & & & $<0.001 \ddagger$ & $0.833 \ddagger$ & $0.058 \ddagger$ \\
\hline \multirow[t]{2}{*}{ Epithelium thickness $(\mu \mathrm{m})$} & $\mathrm{T}$ & $60 \cdot 2$ & $66 \cdot 3^{\mathrm{a}}$ & $55 \cdot 7$ & 81.6 & 3.63 & 0.198 & 0.003 & $<0.001$ & 0.074 \\
\hline & $\mathrm{H}$ & 65.1 & $54.4^{\mathrm{b}}$ & 59.8 & 71.0 & & & $0.198 \ddagger$ & $0.838 \ddagger$ & $0.011 \ddagger$ \\
\hline \multirow[t]{2}{*}{ Stratum corneum thickness $(\mu \mathrm{m})$} & $\mathrm{T}$ & $18 \cdot 0$ & $19 \cdot 0$ & 23.3 & $27 \cdot 7$ & 0.852 & 0.007 & $<0.001$ & 0.007 & 0.350 \\
\hline & $\mathrm{H}$ & $16 \cdot 9$ & $17 \cdot 5$ & $21 \cdot 0$ & $25 \cdot 4$ & & & $0.405 \ddagger$ & $0.898 \ddagger$ & $0.827 \ddagger$ \\
\hline \multirow[t]{2}{*}{ Lamina propria thickness $(\mu \mathrm{m})$} & $\mathrm{T}$ & $82 \cdot 5$ & $73 \cdot 6$ & $65 \cdot 9$ & $60 \cdot 4$ & 3.42 & 0.038 & $<0.001$ & 0.959 & 0.497 \\
\hline & $\mathrm{H}$ & $85 \cdot 6$ & $77 \cdot 5$ & $75 \cdot 8$ & $64 \cdot 8$ & & & $0.653 \ddagger$ & $0.527 \ddagger$ & $0.444 \ddagger$ \\
\hline
\end{tabular}

a,b Mean values for an item within a column are significantly different $(P<0.05)$.

* Digestible energy on a DM basis.

$\dagger \mathrm{E}-\mathrm{L}=$ linear effect of dietary energy level; $\mathrm{E}-\mathrm{Q}=$ quadratic effect of dietary energy level; $\mathrm{E}-\mathrm{C}=$ cubic effect of dietary energy level.

$\ddagger P$ value for the interaction of dietary energy level effect with species.

Table 3. Morphological development of papillae in the ventral sac of the rumen in Tibetan (T) and small-tailed Han (H) sheep offered diets of different energy levels

(Mean values with their pooled standard errors)

\begin{tabular}{|c|c|c|c|c|c|c|c|c|c|c|}
\hline \multirow[b]{2}{*}{ Items } & \multirow[b]{2}{*}{ Breed } & \multicolumn{4}{|c|}{ Dietary energy level (MJ/kg DM*) } & \multirow[b]{2}{*}{ SEM } & \multicolumn{4}{|c|}{$P \dagger$} \\
\hline & & $8 \cdot 21$ & $9 \cdot 33$ & $10 \cdot 45$ & 11.57 & & Breed & $E-L$ & $E-Q$ & $\mathrm{E}-\mathrm{C}$ \\
\hline \multirow[t]{2}{*}{ Papilla surface area $\left(\mathrm{mm}^{2}\right)$} & T & $0.651^{a}$ & $0.482^{a}$ & 0.413 & 0.386 & 0.0268 & $<0.001$ & $<0.001$ & 0.716 & 0.431 \\
\hline & $\mathrm{H}$ & $0.323^{b}$ & $0.378^{\mathrm{b}}$ & 0.415 & 0.356 & & & $<0.001 \ddagger$ & $0.002 \ddagger$ & $0.907 \ddagger$ \\
\hline \multirow[t]{2}{*}{ Papilla height (mm) } & $\mathrm{T}$ & $1 \cdot 21^{\mathrm{a}}$ & $1 \cdot 14^{\mathrm{a}}$ & 0.974 & 1.03 & 0.0561 & 0.007 & 0.657 & 0.782 & 0.913 \\
\hline & $\mathrm{H}$ & $0.865^{b}$ & $0.933^{b}$ & 1.09 & 0.988 & & & $0.002 \ddagger$ & $0.071 \ddagger$ & $0.072 \ddagger$ \\
\hline \multirow[t]{2}{*}{ Papilla width (mm) } & $\mathrm{T}$ & $0.270^{a}$ & 0.212 & 0.212 & $0 \cdot 189$ & 0.0079 & $<0.001$ & $<0.001$ & $0.741^{\top}$ & 0.364 \\
\hline & $\mathrm{H}$ & $0.187^{b}$ & 0.204 & 0.190 & 0.179 & & & $<0.001 \ddagger$ & $0.009 \ddagger$ & $0.028 \ddagger$ \\
\hline \multirow[t]{2}{*}{ Epithelium thickness ( $\mu \mathrm{m})$} & $\mathrm{T}$ & $79 \cdot 2$ & $66 \cdot 7$ & 57.5 & $63 \cdot 0$ & 2.46 & 0.097 & $<0.001$ & $<0.001$ & 0.132 \\
\hline & $\mathrm{H}$ & $70 \cdot 9$ & $64 \cdot 1$ & $57 \cdot 0$ & $62 \cdot 5$ & & & $0.110 \ddagger$ & $0.432 \ddagger$ & $0.924 \ddagger$ \\
\hline \multirow[t]{2}{*}{ Stratum corneum thickness $(\mu \mathrm{m})$} & $\mathrm{T}$ & $24 \cdot 8$ & $22 \cdot 6$ & $22 \cdot 1$ & $19 \cdot 2$ & 0.68 & $<0.001$ & $<0.001$ & 0.391 & 0.382 \\
\hline & $\mathrm{H}$ & $22 \cdot 4$ & $20 \cdot 9$ & 18.9 & $18 \cdot 3$ & & & $0.076 \ddagger$ & $0.098 \ddagger$ & $0.101 \ddagger$ \\
\hline \multirow[t]{2}{*}{ Lamina propria thickness $(\mu \mathrm{m})$} & $\mathrm{T}$ & $73 \cdot 1$ & 74.4 & $67 \cdot 8^{\mathrm{b}}$ & $63 \cdot 6^{\mathrm{b}}$ & 5.01 & 0.003 & 0.185 & 0.720 & 0.783 \\
\hline & $\mathrm{H}$ & 69.5 & $76 \cdot 9$ & $85 \cdot 1^{a}$ & $92 \cdot 8^{a}$ & & & $0.002 \ddagger$ & $0.686 \ddagger$ & $0.715 \ddagger$ \\
\hline
\end{tabular}

a,b Mean values for an item within a column are significantly different $(P<0.05)$.

* Digestible energy on a DM basis.

$\dagger \mathrm{E}-\mathrm{L}=$ linear effect of dietary energy level; $\mathrm{E}-\mathrm{Q}=$ quadratic effect of dietary energy level; $\mathrm{E}-\mathrm{C}=$ cubic effect of dietary energy level.

$\ddagger P$ value for the interaction of dietary energy level effect with species.

the two lowest energy levels (Table 3). In addition, the papillae width was greater in Tibetan than in small-tailed Han sheep at the lowest energy level (linear dietary energy level $\times$ breed, $P<0 \cdot 001)$ and decreased linearly $(P<0 \cdot 001)$ with an increase in dietary energy level in both breeds. The epithelium thickness of ruminal papillae decreased linearly with an increase in dietary energy level $(P<0.001)$ and did not differ between breeds $(P>0.05)$, whereas the stratum corneum thickness of ruminal papillae also decreased linearly $(P<0.001)$, but was thicker in Tibetan than in small-tailed Han sheep $(P<0 \cdot 01)$. The lamina propria of ruminal papillae were thicker in small-tailed Han sheep at the two highest dietary energy levels (linear dietary energy level $\times$ breed, $P=0 \cdot 002$ ). Representative micrographs are presented in online Supplementary Fig. S3.

\section{Expression of SCFA absorption relative genes in the} rumen dorsal sac epithelium

The relative expression of MCT1 mRNA in the rumen dorsal sac was higher in Tibetan than in small-tailed Han sheep at the lowest energy level (Fig. 2(a)), but was higher in small-tailed Han sheep at the dietary energy levels of 9.33 and $10.45 \mathrm{MJ} / \mathrm{kg}$ (quadratic dietary energy level $\times$ breed, $P<0 \cdot 001$ ). In addition, the immunohistochemistry results of the MCT1 protein expression showed the same pattern (micrographs are presented in Fig. 2(a)). The MCT2 mRNA relative expression was higher in Tibetan than in small-tailed Han sheep (quadratic dietary energy level $\times$ breed, $P<0.001)$ at the lowest and highest energy levels (Fig. 2(b)), and its protein expression showed the same pattern (Fig. 2(b)). The MCT4 mRNA relative expression was higher 
(a)

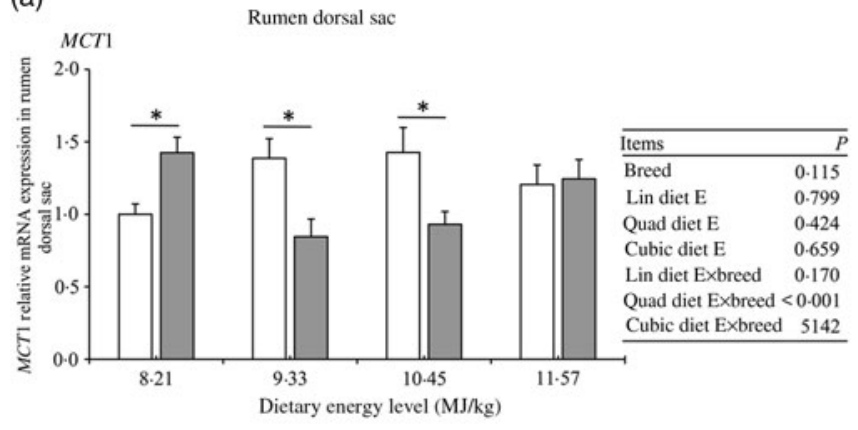

(b)
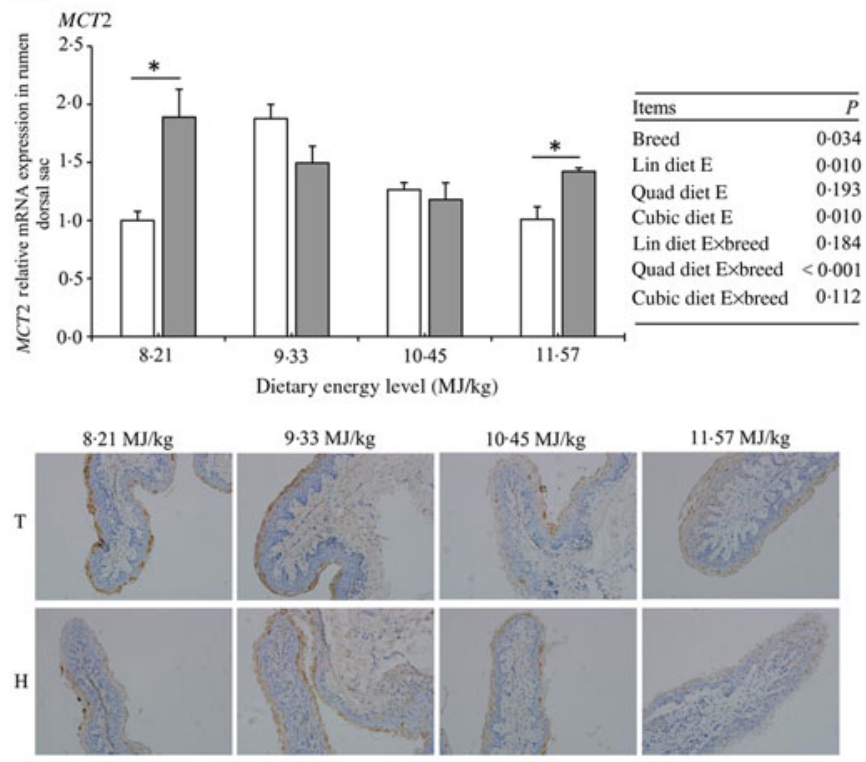

(c)
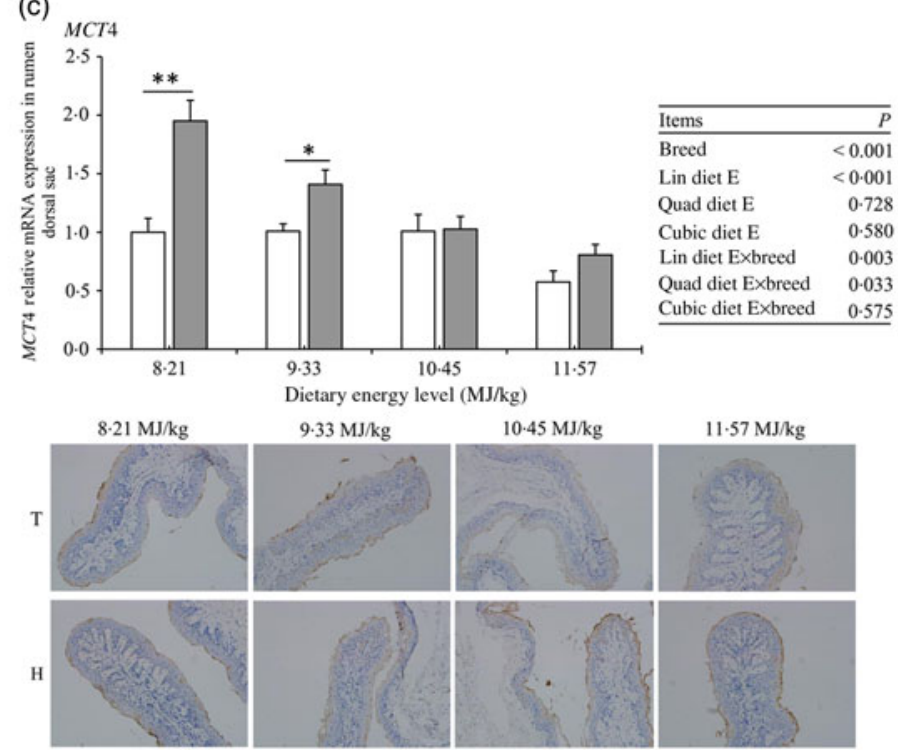

Fig. 2. Expression of monocarboxylate transporter $(M C T)$ mRNA and immunohistochemistry in the rumen dorsal sac epithelium of Tibetan (T) and small-tailed Han (H) sheep offered diets of different energy $(E)$ levels. The dietary energy levels are digestible energy on a DM basis. Cells with brown-stained cytoplasm are positive cells in the representative micrographs of immunohistochemistry analysis; magnification 200x. ${ }^{*} P<0.05,{ }^{\star *} P<0.01$. $\square$, Small-tailed Han sheep; $\square$, Tibetan sheep. Lin, linear; Quad, quadratic.

in Tibetan than in small-tailed Han sheep at the two lowest energy levels (linear dietary energy level $\times$ breed, $P=0.003$ ) and decreased linearly $(P<0 \cdot 001)$ as the dietary energy level increased (Fig. 2(c)).

The expression of DRA mRNA increased linearly $(P<0 \cdot 001)$ with an increase in dietary energy level (Fig. 3(a)) in the rumen dorsal sac, but no difference was found between breeds $(P>0.05)$. However, with an increase in dietary energy level, the NCB1 mRNA relative expression decreased linearly $(P<0.001)$ and was higher in Tibetan than in small-tailed Han sheep (linear dietary energy level $\times$ breed, $P=0 \cdot 001$ ) at the lowest energy level (Fig. 3(b)) and the expression of PAT1 mRNA also decreased linearly $(P<0.001)$ (Fig. 3(c)) and was higher in Tibetan than in small-tailed Han sheep at the lowest and highest energy levels, but was higher in small-tailed Han than in Tibetan sheep at the two other energy levels (quadratic dietary energy level $\times$ breed, $P<0 \cdot 001)$. The AE2 mRNA expression decreased linearly $(P<0.001)$ with an increase in dietary energy level (Fig. 4(a)) and was higher in Tibetan than in small-tailed Han sheep at the lowest energy level (quadratic dietary energy level $\times$ breed, $P=0.033$ ), while its protein expression showed the same pattern (Fig. 4(a)).

The expression of NHE1 mRNA decreased linearly $(P<0.001)$ in both breeds (Fig. 5(a)) and was higher in 
High SCFA absorption ability in Tibetan sheep
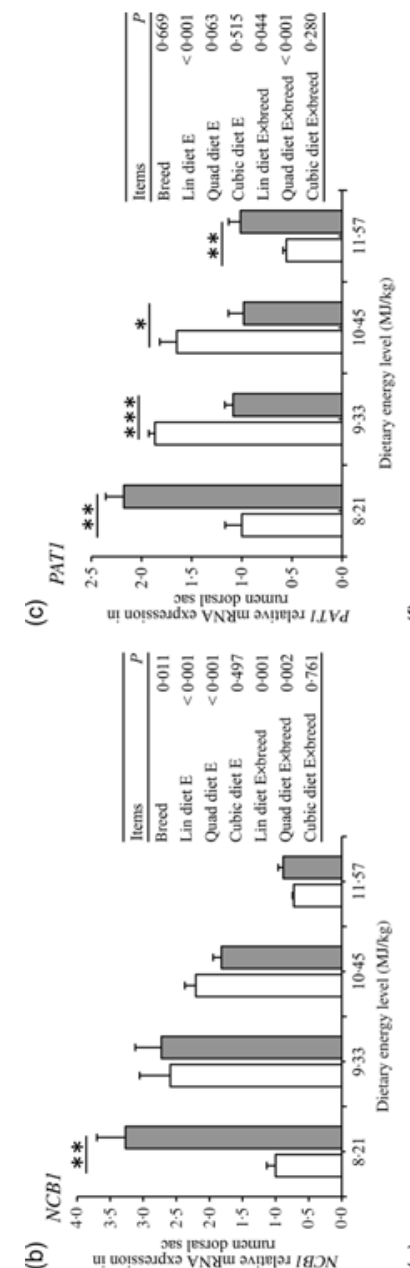

a

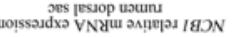

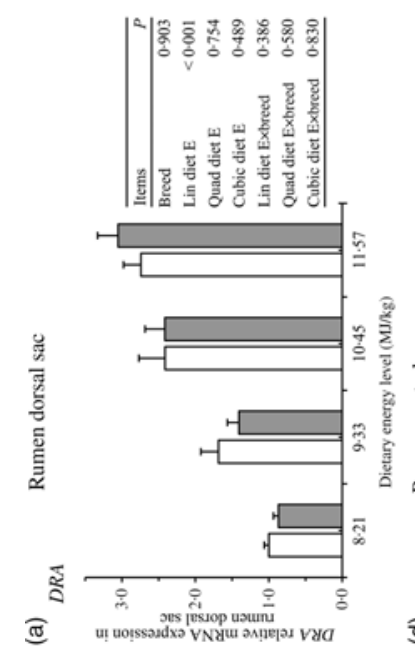

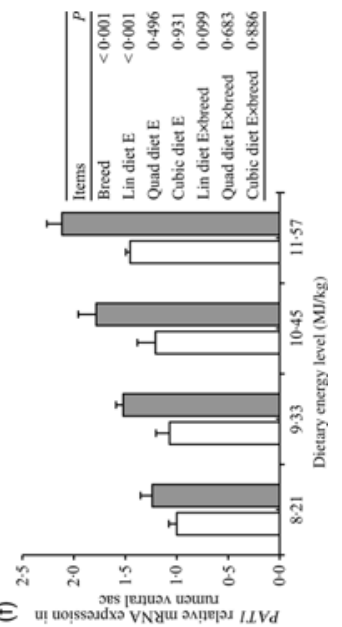

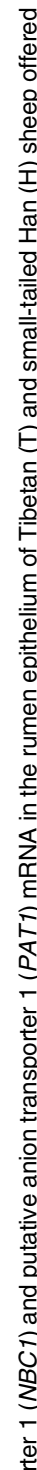

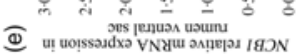
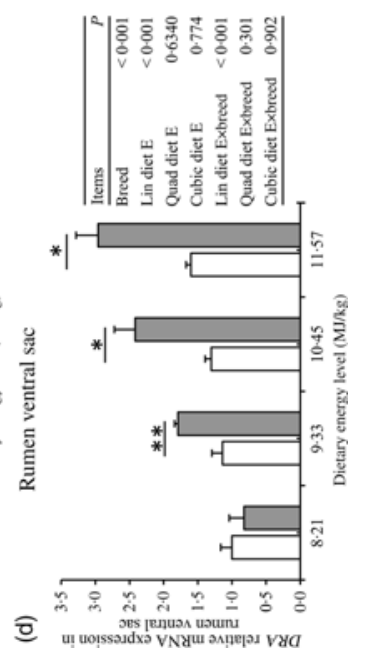

Tibetan than in small-tailed Han sheep at the lowest and highest energy levels (quadratic dietary energy level $\times$ breed, $P=0.039$ ), and its protein expression showed the same pattern (Fig. 5(a)). In addition, the NHE3 mRNA expression increased quadratically $(P<0.001)$ with an increase in dietary energy level (Fig. 5(b)) and was higher in Tibetan than in small-tailed Han sheep at the lowest energy level, but was higher in small-tailed Han than in Tibetan sheep at the highest energy level. Its protein expression showed the same results (Fig. 5(b)).

The $\mathrm{Na}^{+} / \mathrm{K}^{+}$-ATPase mRNA expression deceased linearly as the dietary energy level increased $(P<0 \cdot 001$; Fig. 6(a)) and was higher in small-tailed Han than in Tibetan sheep at the lowest energy level (linear dietary energy level $\times$ breed, $P=0 \cdot 002$ ), and the protein expression results showed the same pattern (Fig. 6(a)). The $\nu H^{+}$-ATPase mRNA expression decreased linearly as the dietary energy level increased $(P<0.001$, Fig. 7(a)) and was higher in Tibetan than small-tailed Han sheep at the lowest energy level (quadratic dietary energy level $x$ breed, $P=0.009$ ), while the protein expression results showed the same pattern (Fig. 7(a)).

\section{Expression of SCFA absorption relative genes in the rumen ventral sac epithelium}

The relative expression of MCT1 mRNA increased linearly $(P<0.001)$ with an increase in dietary energy level in the rumen ventral sac (Fig. 8(a)) and was higher in Tibetan than in smalltailed Han sheep at the two lowest energy levels, but was higher in small-tailed Han sheep at the highest dietary energy level (linear dietary energy level $\times$ breed, $P<0.001$ ). In addition, the immunohistochemistry results of the MCT1 protein expression exhibited the same pattern (Fig. 8(a)). The MCT2 mRNA relative expression increased linearly $(P<0.001)$ as the dietary energy level increased (Fig. 8(b)) and was higher in Tibetan than in small-tailed Han sheep at the dietary energy level of $9.33 \mathrm{MJ} / \mathrm{kg}$ (quadratic dietary energy level $\times$ breed, $P=0.034$ ), while its protein expression results showed the same pattern (Fig. 8(b)). The MCT4 mRNA relative expression increased linearly $(P<0.001)$ as the dietary energy level increased (Fig. 8(c)), and there was no difference between breeds $(P>0.05)$.

The expression of DRA mRNA increased linearly $(P<0.001)$ with an increase in dietary energy level in the rumen ventral sac (Fig. 3(d)) and was higher in Tibetan than in small-tailed Han at the three higher energy levels (linear dietary energy level $x$ breed, $P<0 \cdot 001)$. The NCB1 mRNA relative expression also increased linearly $(P<0.001)$ as the dietary energy level increased and was higher in small-tailed Han than in Tibetan sheep (linear dietary energy level $\times$ breed, $P=0.025$ ) at the two highest energy levels (Fig. 3(e)). The expression of PAT1 mRNA increased linearly $(P<0.001)$ as the dietary energy level increased (Fig. 3(f)) and was higher in Tibetan than in smalltailed Han sheep $(P<0 \cdot 001)$. In addition, the $A E 2$ mRNA expression also increased linearly $(P<0.001)$ in both breeds as the dietary energy level increased (Fig. 4(b)) and was higher in Tibetan than in small-tailed Han sheep at the dietary energy levels of 9.33 and $10.45 \mathrm{MJ} / \mathrm{kg}$ (quadratic dietary energy level $\times$ 
(a)
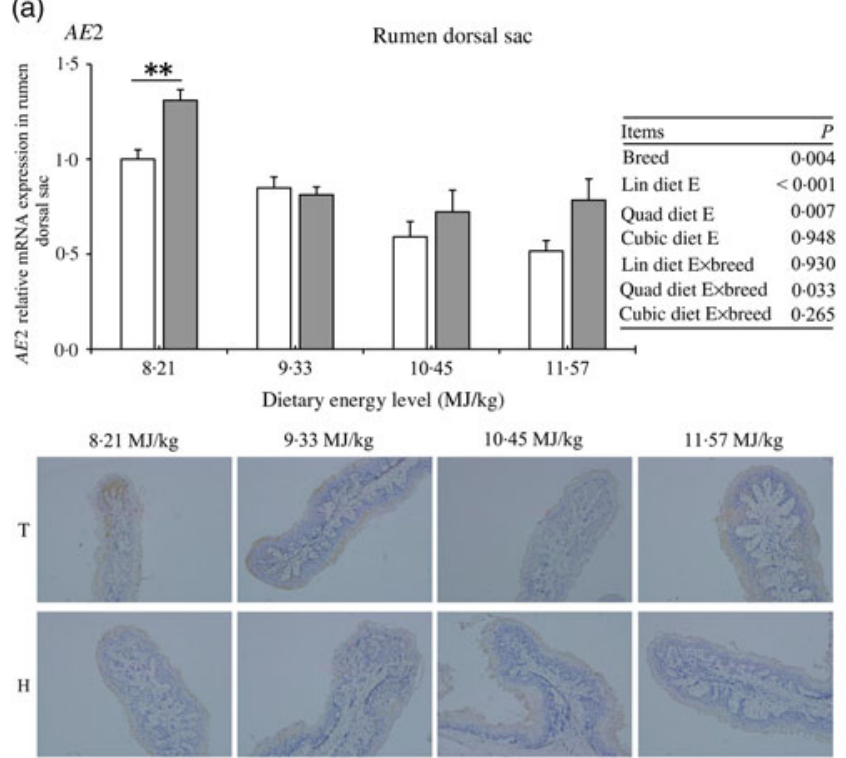

(b)
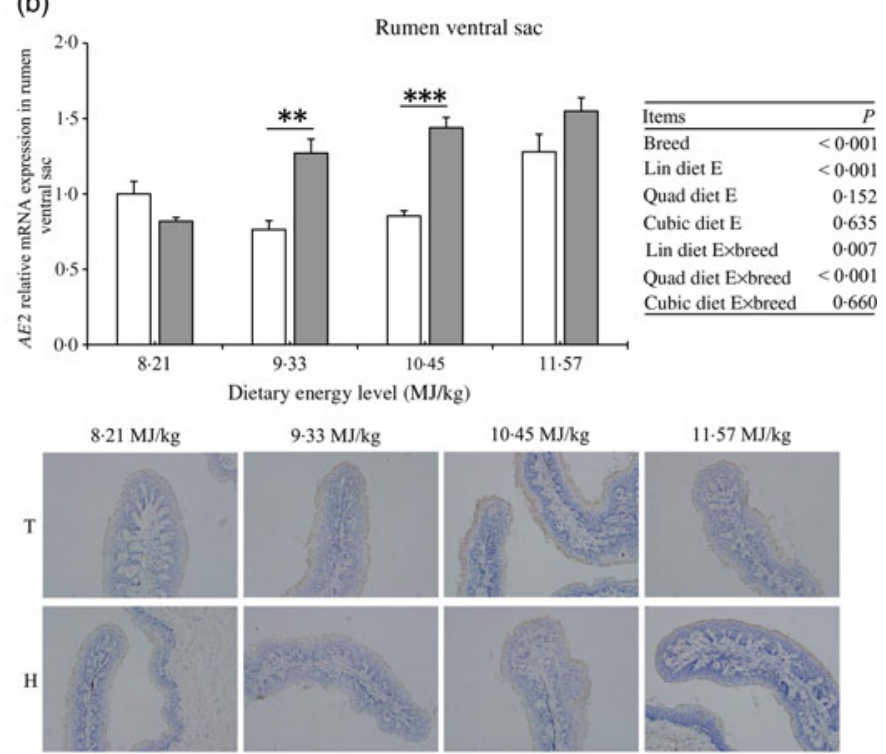

Fig. 4. Expression of anion exchanger 2 (AE2) mRNA and immunohistochemistry in the rumen epithelium of Tibetan (T) and small-tailed Han (H) sheep offered diets of different energy $(E)$ levels. The dietary energy levels are digestible energy on a DM basis. The cells with the brown-stained cytoplasm were the positive cells in the representative micrographs of immunohistochemistry analysis; magnification 200x. ${ }^{* \star} P<0.01,{ }^{* \star *} P<0.001$. $\square$, Small-tailed Han sheep; $\square$, Tibetan sheep. Lin, linear; Quad, quadratic.

(a)
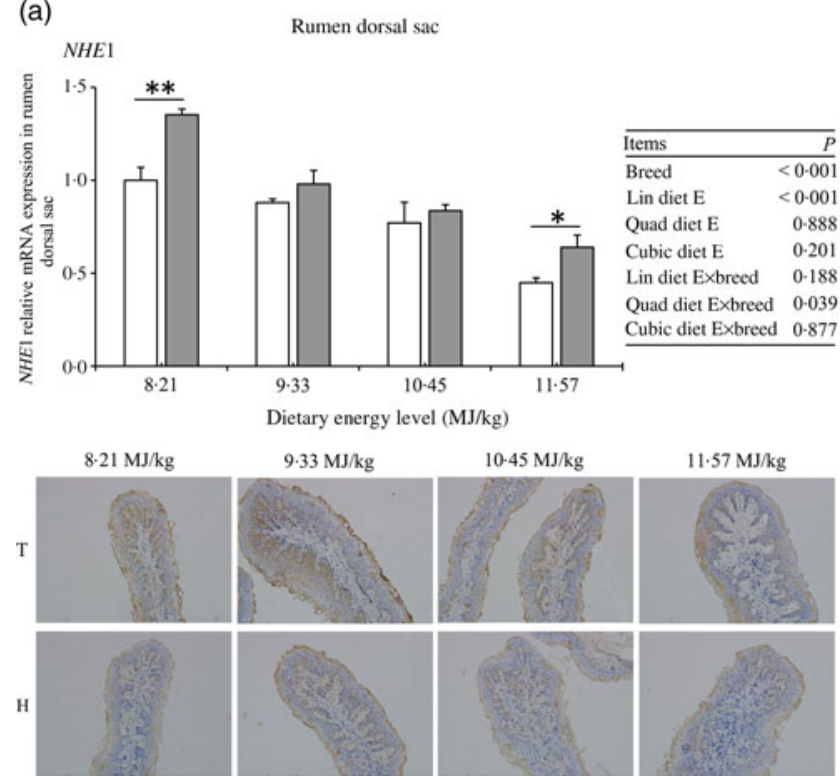

$11.57 \mathrm{MJ} / \mathrm{kg}$

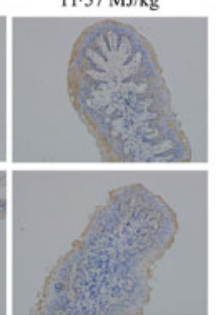

(b)
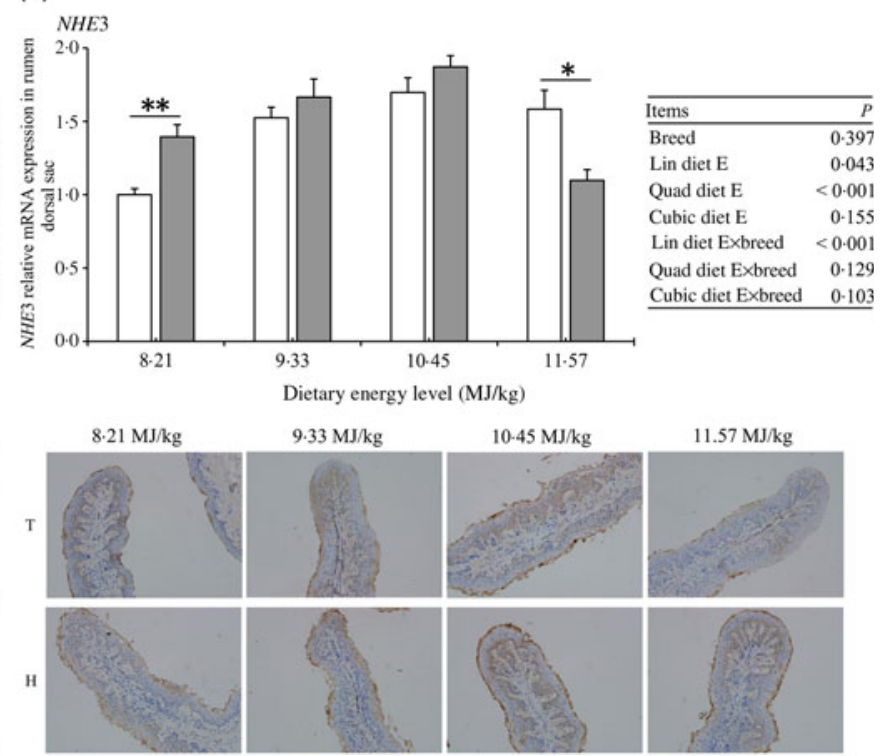

Fig. 5. Expression of sodium/hydrogen antiporter (NHE) mRNA and immunohistochemistry in the rumen dorsal sac epithelium of Tibetan (T) and small-tailed Han (H) sheep offered diets of different energy $(E)$ levels. The dietary energy levels are digestible energy on a DM basis. The cells with the brown-stained cytoplasm were the positive cells in the representative micrographs of immunohistochemistry analysis; magnification 200x. ${ }^{\star} P<0.05,{ }^{\star \star} P<0.01$. $\square$, Small-tailed Han sheep; $\square$, Tibetan sheep. Lin, linear; Quad, quadratic.

breed, $P<0 \cdot 001)$, while its protein expression showed the same pattern (Fig. 4(b)).

The expression of NHE1 mRNA increased linearly $(P<0.001)$ with an increase in dietary energy level (Fig. $9($ a)), but there was no difference between breeds $(P>0.05)$, while its protein expression showed the same pattern (Fig. 9(a)). With an increase in dietary energy level, the NHE3 mRNA expression increased linearly $(P<0.001$; Fig. $9(\mathrm{~b}))$ and was higher in Tibetan than in small-tailed Han sheep $(P=0 \cdot 025)$, and its protein expression exhibited the same results (Fig. 9(b)).

The $\mathrm{Na}^{+} / \mathrm{K}^{+}$-ATPase mRNA expression increased linearly $(P=0.001)$ in both breeds as the dietary energy level increased (Fig. 6(b)), but there was no difference between breeds $(P>0.05)$, and the protein expression showed the same pattern (Fig. 6(b)). The $\nu H^{+}$-ATPase decreased quadratically $(P<0 \cdot 001)$ with an increase in dietary energy level (Fig. 7(b)) 
(a)
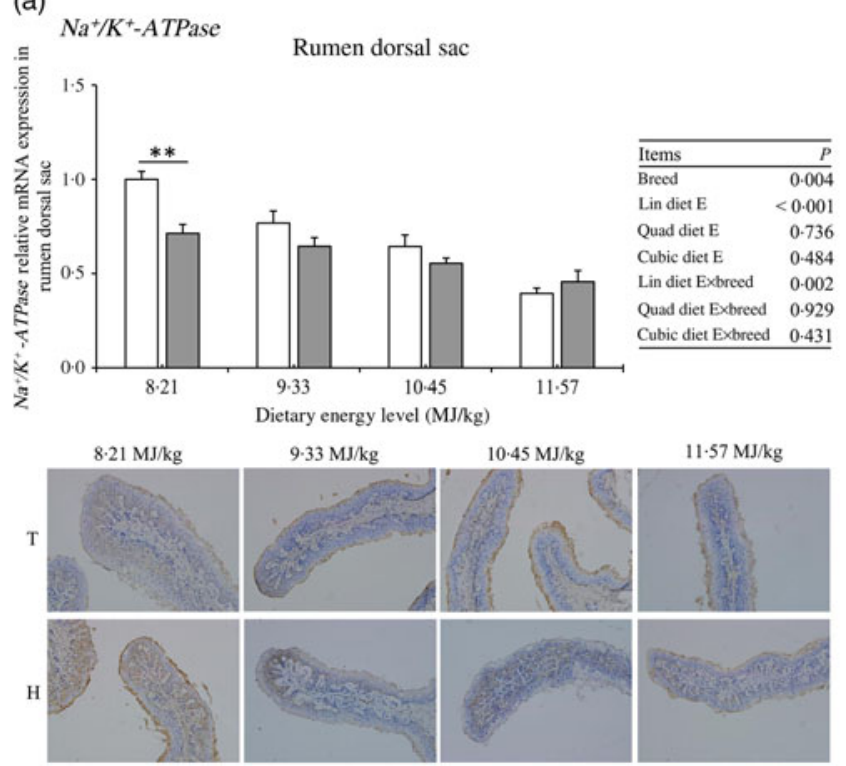

(b)
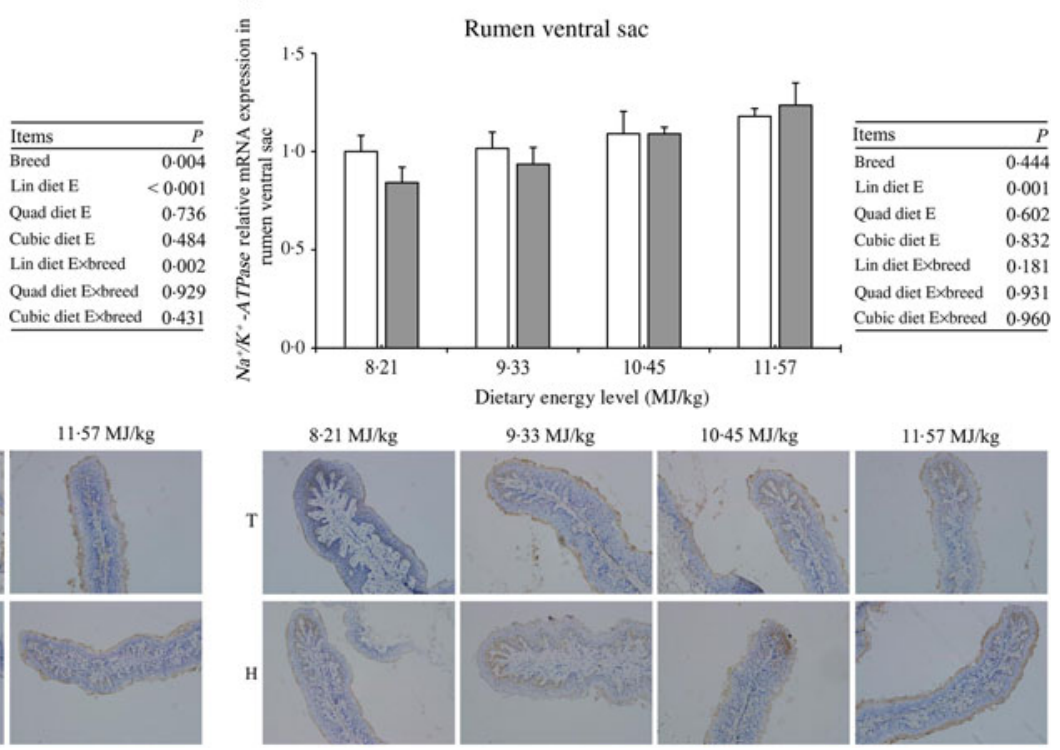

Fig. 6. Expression of sodium/potassium ATPase $\left(\mathrm{Na}^{+} / \mathrm{K}^{+}\right.$-ATPase) mRNA and immunohistochemistry in the rumen epithelium of Tibetan $(\mathrm{T})$ and small-tailed Han $(\mathrm{H})$ sheep offered diets of different energy $(E)$ levels. The dietary energy levels are digestible energy on a DM basis. The cells with the brown-stained cytoplasm were the positive cells in the representative micrographs of immunohistochemistry analysis; magnification $200 \times$. ${ }^{\star *} P<0.01$. $\square$, Small-tailed Han sheep; $\square$, Tibetan sheep. Lin, linear; Quad, quadratic.

(a)
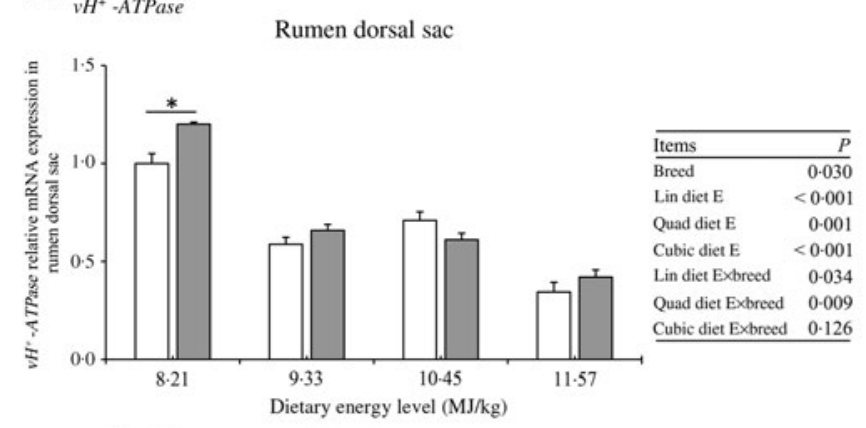

$11.57 \mathrm{MJ} / \mathrm{kg}$

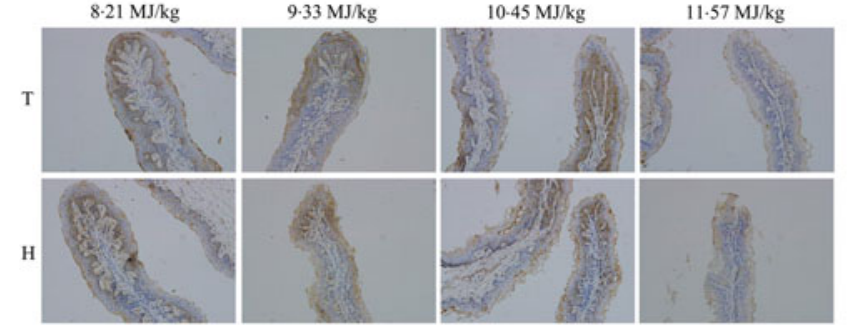

(b)
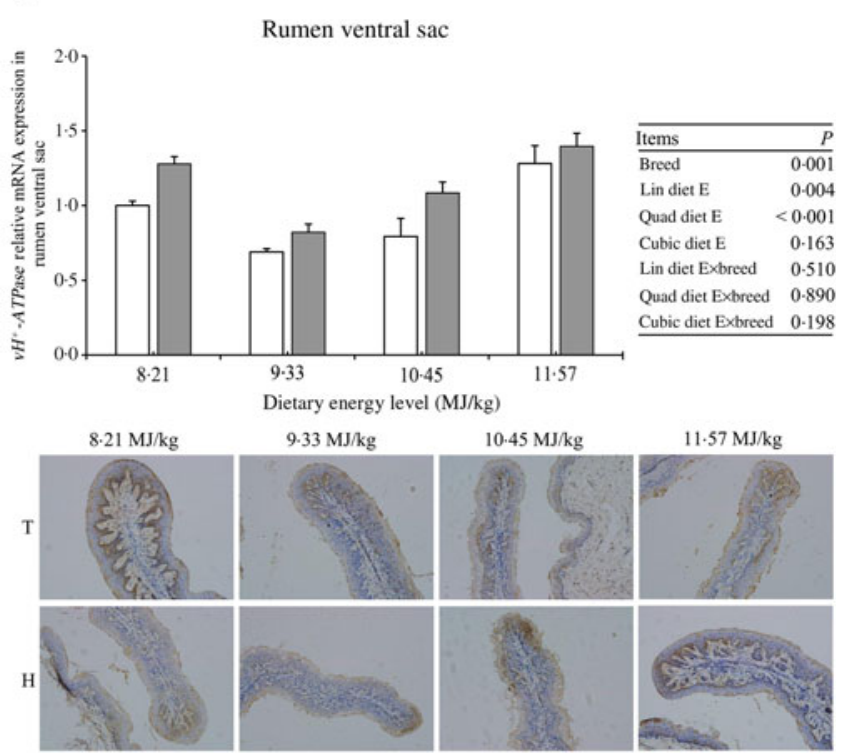

Fig. 7. Expression of vacuolar-type ATPase $\left(\nu H^{+}\right.$-ATPase $)$mRNA and immunohistochemistry in the rumen epithelium of Tibetan $(T)$ and small-tailed Han $(H)$ sheep offered diets of different energy $(E)$ levels. The dietary energy levels are digestible energy on a DM basis. The cells with the brown-stained cytoplasm were the positive cells in the representative micrographs of immunohistochemistry analysis; magnification $200 \times$. ${ }^{*} P<0.05$. $\square$, Small-tailed Han sheep; $\square$, Tibetan sheep. Lin, linear; Quad, quadratic.

and was higher in Tibetan than in small-tailed Han sheep $(P=0.001)$, while the protein expression exhibited the same pattern (Fig. 7(b)).

\section{Expression of SCFA metabolism and metabolism regulation relative genes in the rumen dorsal sac epithelium}

The expression of ACAT1 mRNA decreased linearly $(P<0.001)$ as the dietary energy level increased (Fig. 10(a)) and was higher in small-tailed Han than in Tibetan sheep at the three lower energy levels (linear dietary energy level $\times$ breed, $P=0 \cdot 010$ ), while the HMGCS2 mRNA expression increased quadratically $(P<0 \cdot 001)$ with an increase in dietary energy level (Fig. 10(b)) and was higher in small-tailed Han sheep than in Tibetan sheep at the two lowest energy levels (linear dietary energy level $x$ breed, $P=0.006)$. The expression of $P P A R-\alpha$ mRNA increased quadratically $(P<0.001)$ as the dietary energy level increased 
(a)

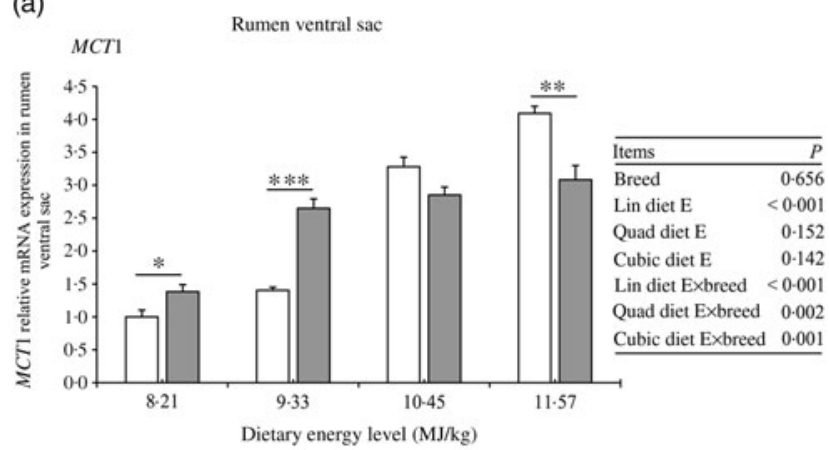

(b)
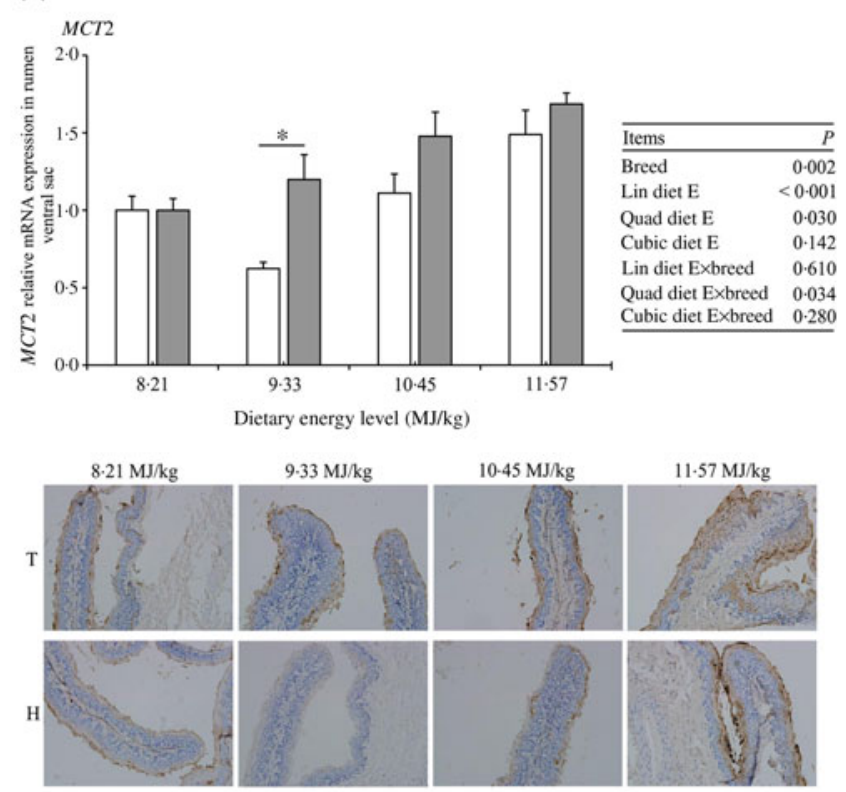

(c) ${ }_{\text {MCT4 }}$
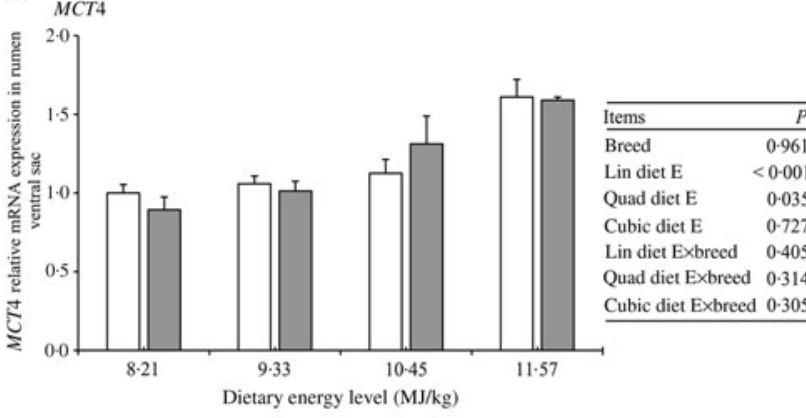

Lin $\operatorname{diet} \mathrm{E} \quad<0-001$

Quad diet E $\quad 0.035$

Cubic diet $\mathrm{E} \quad 0-727$

Lin diet Exbreed $\quad 0.405$

Quad diet Exbreed 0.314

Cubic diet Exbreed 0-305

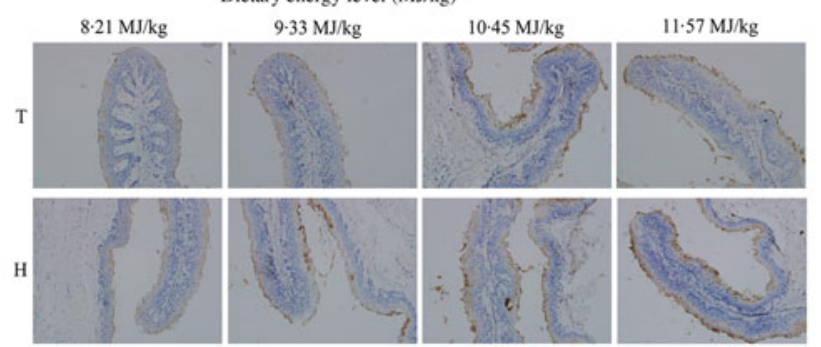

Fig. 8. Expression of monocarboxylate cotransporter (MCT) mRNA and immunohistochemistry in the rumen ventral sac epithelium of Tibetan (T) and small-tailed Han $(\mathrm{H})$ sheep offered diets of different energy $(\mathrm{E})$ levels. The dietary energy levels are digestible energy on a DM basis. Cells with brown-stained cytoplasm are positive cells in the representative micrographs of immunohistochemistry analysis; magnification $200 \times$. ${ }^{\star} P<0.05,{ }^{\star *} P<0.01,{ }^{\star \star *} P<0.001$. $\square$, Small-tailed Han sheep; $\square$, Tibetan sheep. Lin, linear; Quad, quadratic.

(Fig. 10(c)) and was higher in Tibetan than in small-tailed Han sheep $(P=0 \cdot 040)$.

The ACAT2 mRNA relative expression increased quadratically $(P=0.015)$ in both breeds as the dietary energy level increased (Fig. 11(a)) and was higher in Tibetan than in smalltailed Han sheep $(P=0.023)$. In contrast, the HMGCS1 mRNA relative expression decreased quadratically $(P<0.001)$ as the dietary energy level increased (Fig. 11(b)), and there was no difference between breeds $(P>0 \cdot 05)$. In addition, the relative expressions of $H M G C R$ and SREBP2 mRNA were higher in Tibetan than in small-tailed Han sheep at the two highest energy levels (linear dietary energy level $\times$ breed, $P<0 \cdot 001$, Fig. 11(c) and (d)).

\section{Expression of SCFA metabolism and metabolism regulation relative genes in the rumen ventral sac epithelium}

The expression of ACAT1 mRNA increased quadratically $(P<0.001)$ as the dietary energy level increased (Fig. 10(d)) and was higher in small-tailed Han than in Tibetan sheep ( $P=0.007)$, whereas the HMGCS2 mRNA expression increased linearly $(P<0.001$, Fig. 10(e)) with an increase in dietary energy level and was also higher in small-tailed Han than in Tibetan 
(a)

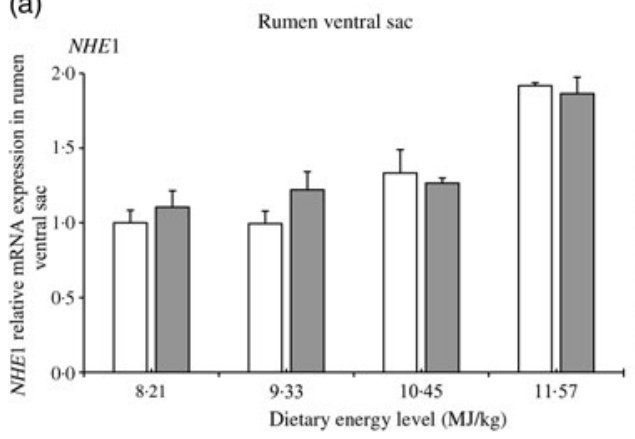

(b)
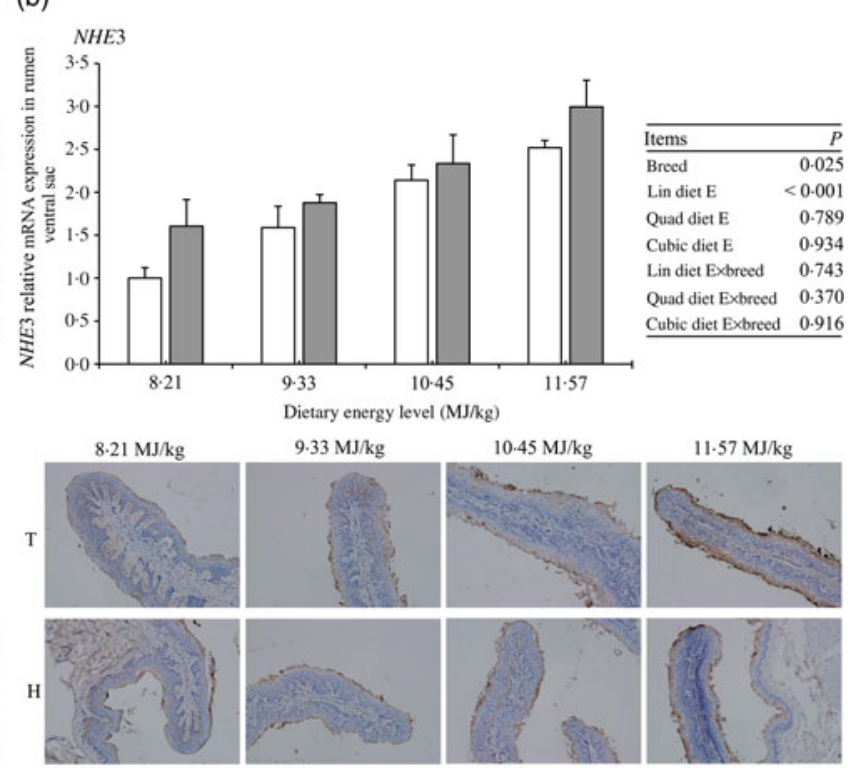
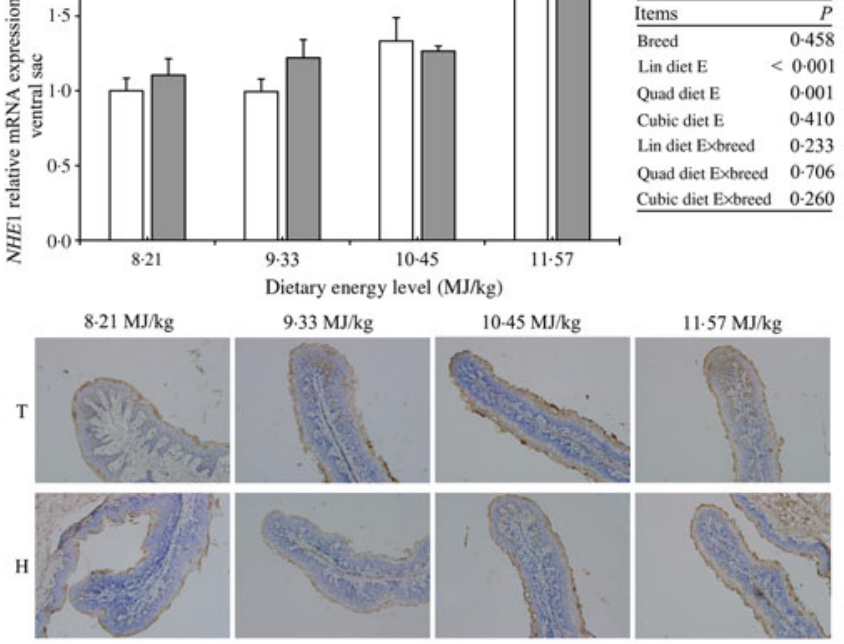

Fig. 9. Expression of sodium/hydrogen antiporter (NHE) mRNA and immunohistochemistry in the rumen ventral sac epithelium of Tibetan ( $\mathrm{T}$ ) and small-tailed Han (H) sheep offered diets of different energy (E) levels. The dietary energy levels are digestible energy on a DM basis. The cells with the brown-stained cytoplasm were the positive cells in the representative micrographs of immunohistochemistry analysis; magnification 200×. $\square$, Small-tailed Han sheep; $\square$, Tibetan sheep. Lin, linear; Quad, quadratic.

sheep $(P<0 \cdot 001)$. The expression of PPAR- $\alpha$ mRNA increased linearly $(P<0.001)$ as the dietary energy level increased (Fig. 10(f)) and was higher in Tibetan than in small-tailed Han sheep $(P=0 \cdot 001)$.

The ACAT2 mRNA relative expression decreased linearly $(P<0.001)$ as the dietary energy level increased (Fig. 12(a)), and there was no difference between breeds $(P>0 \cdot 05)$, while the HMGCS1 mRNA relative expression decreased linearly $(P<0 \cdot 001)$ as the dietary energy level increased (Fig. 12(b)), but was higher in Tibetan than in small-tailed Han sheep at all four energy levels (linearly dietary energy level $\times$ breed, $P<0.001)$. The HMGCR mRNA relative expression decreased quadratically $(P<0.001)$ as the dietary energy level increased (Fig. 12(c)) and was higher in Tibetan than in small-tailed Han sheep $(P<0 \cdot 001)$. The relative expression of SREBP 2 mRNA also decreased quadratically $(P<0.001)$ as the dietary energy level increased and was higher in Tibetan than in small-tailed Han sheep at the two highest energy levels (linear dietary energy level $\times$ breed, $P=0 \cdot 001$, Fig. 12(d)).

\section{Discussion}

\section{Effect of dietary energy level on rumen SCFA production} and growth performance

In ruminants, carbohydrates are fermented by microbial activity in the rumen and converted to SCFA and, subsequently, serve as the principle energy source by contributing up to $80 \%$ of their energy requirements ${ }^{(6)}$. Consequently, a high yield of SCFA is required for a high level of performance in ruminants and a sufficient source of nutrients intake is a key determinant. In the present study, SCFA and average daily gain increased linearly in both breeds as the dietary energy level increased and both were higher in Tibetan than in small-tailed Han sheep across treatments. The difference in total SCFA yield between breeds occurred even though there was no difference in digestible energy intake between breeds and was a result, at least in part, of the higher nutrient digestibilties in Tibetan than in small-tailed Han sheep ${ }^{(13)}$. Higher yield of SCFA in Tibetan sheep than in lowland sheep was reported in an in vitro study ${ }^{(4)}$. The molar proportions of individual SCFA in the rumen are of considerable interest and importance and are dependent on dietary intake. For example, a neutral-detergent fibre-based diet led to high molar proportions of acetate, a starch-based diet led to high molar proportions of propionate and a high-pectin diet led to high molar proportion of butyrate ${ }^{(22)}$. As the dietary energy level increased in the present study, the neutral-detergent fibre and acid-detergent fibre contents decreased linearly, which was consistent with the linear decrease in molar proportions of acetate. In addition, our previous studies demonstrated a higher fibre digestibility in Tibetan than in small-tailed Han sheep ${ }^{(13)}$, which explained the higher molar proportions of acetate in Tibetan sheep and suggested that the Tibetan sheep were better able to cope with a roughage-based diet. However, the molar proportions of propionate were higher in small-tailed Han than in Tibetan sheep, which suggested that the small-tailed Han sheep were more adapted to a starch-based diet. This premise fits in well with their background as small-tailed Han sheep are generally raised in feedlots under intensive management and consume a high proportion of concentrate feed in their diet. Ruminal branched-chain SCFA are mainly end products of protein fermentation and are considered a growth factor for fibre-degrading micro-organisms in the rumen ${ }^{(23,24)}$. Furthermore, they are essential nutritional requirements for most fibre-degrading 

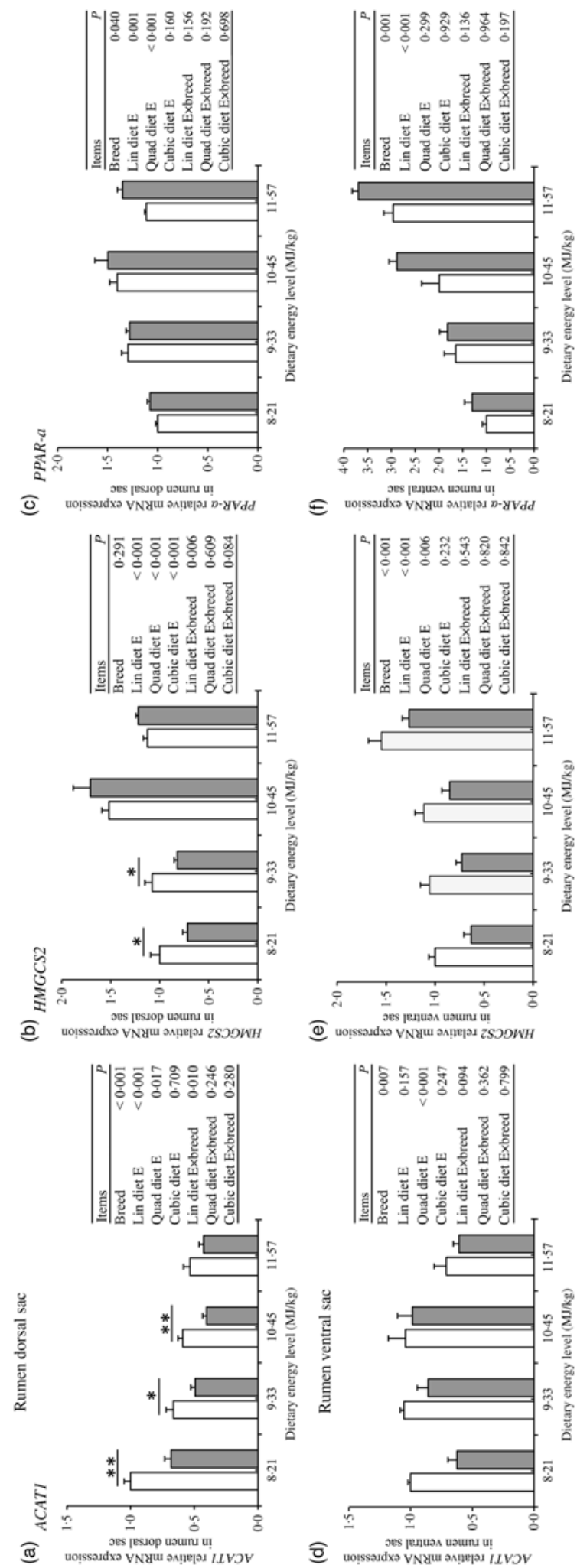

()

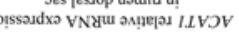

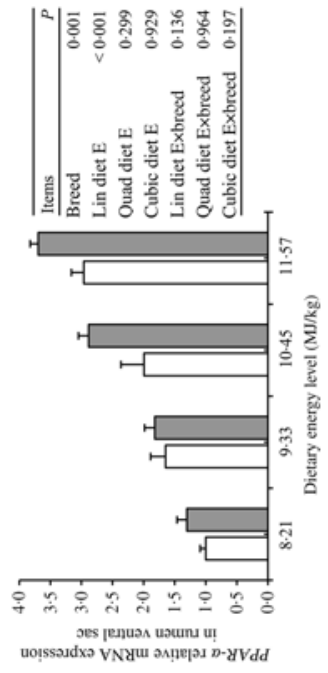

$E$

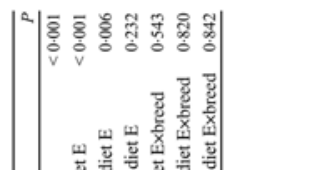

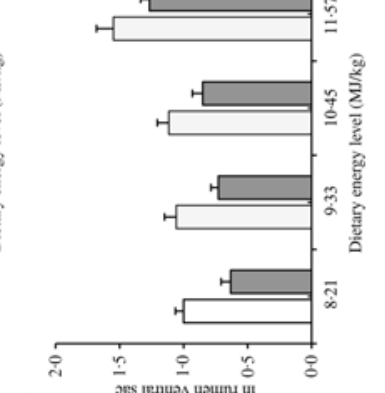

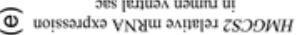

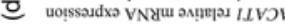

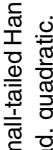 \\ micro-organisms in the rumen ${ }^{(25)}$ and, therefore, the higher molar proportions of iso-acids in Tibetan sheep supported the higher fibre digestibility. \\ Effect of dietary energy level on ruminal papillae morphology development}

The ruminal epithelium is essential and responsible for SCFA absorption and transport. A large proportion of SCFA are absorbed directly across the ruminal epithelium, making the absorption of SCFA a key determinant in the supply of energy for ruminants ${ }^{(5,6)}$. When more SCFA are available for absorption, the ruminal epithelium responds by increasing the size of the rumen papillae, thereby increasing the surface area and the absorptive capacity for SCFA ${ }^{(26)}$. Therefore, the higher density and surface area in Tibetan than small-tailed Han sheep were consistent with the higher SCFA production in Tibetan sheep, which also meant a greater absorptive capacity for SCFA. The development and renewal of rumen papillae depend on adequate nutrient intake ${ }^{(10)}$, which explains the increase in papillae density as the dietary energy level increased in the dorsal sac. In addition, it was reported that increasing the proportion of concentrate in the diet resulted in an increase in ruminal papillae density in calves ${ }^{(27)}$, which supported our observations that rumen papillae density in the dorsal sac increased in both breeds as the dietary energy level increased. However, this is in contrast to our findings in the rumen ventral sac. We reasoned that the dorsal and ventral sacs developed different patterns to adapt to differing dietary energy intakes. In the ventral sac, the expression of the SCFA absorption-related genes increased instead of increasing papillae density with increased SCFA. Furthermore, the development of the ruminal papillae was attributed to epithelial proliferation and differentiation ${ }^{(11)}$, and the SCFA, and mainly butyric acid, are considered essential in the regulation of rumen epithelial proliferation and enhancement of the growth of rumen papillae ${ }^{(28)}$. Consequently, the higher molar proportions of butyrate in Tibetan than small-tailed Han sheep explained, at least in part, the higher papillae density and surface area in Tibetan sheep.

The thickness of the stratum corneum generally increases as a response of the ruminal epithelium to a high-grain diet and high SCFA production ${ }^{(29,30)}$, which is consistent with the stratum corneum thickness increase in the ventral sac as the dietary energy level increased in the present study. In addition, the thicker stratum corneum in Tibetan than in small-tailed Han sheep fits in well with the higher SCFA production in Tibetan sheep. However, the stratum corneum contains a large amount of keratin in the cytoplasm that acts as a physical barrier and hinders the absorption of SCFA by the epithelium ${ }^{(30)}$. Therefore, the increase in papillae density and absorption surface area compensated for the decreased transport rate due to the increased stratum corneum thickness. The decreased stratum corneum thickness in the ventral sac with the increase in dietary energy level was actually beneficial for the absorption of the increased SCFA. The lamina propria, adjacent to the epithelial layer, contains large amounts of capillaries and is responsible for the transfer of SCFA after absorption. A thickening of the lamina propria was a response to the decrease in rumen $\mathrm{pH}$ as SCFA increased 
(a)

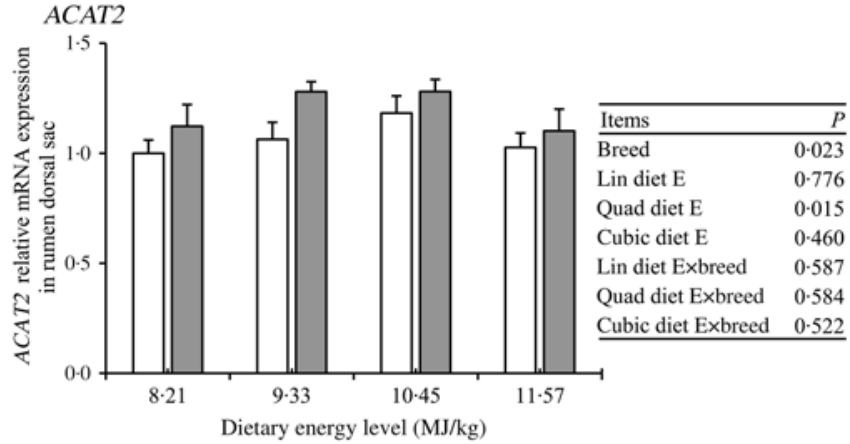

(c)

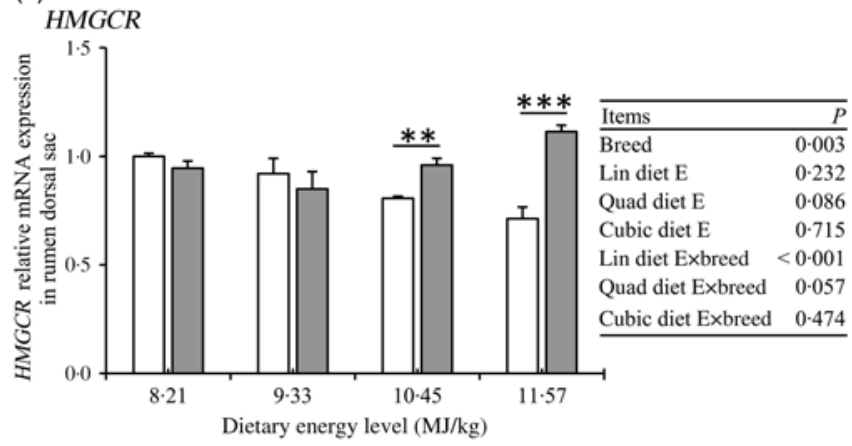

(b)

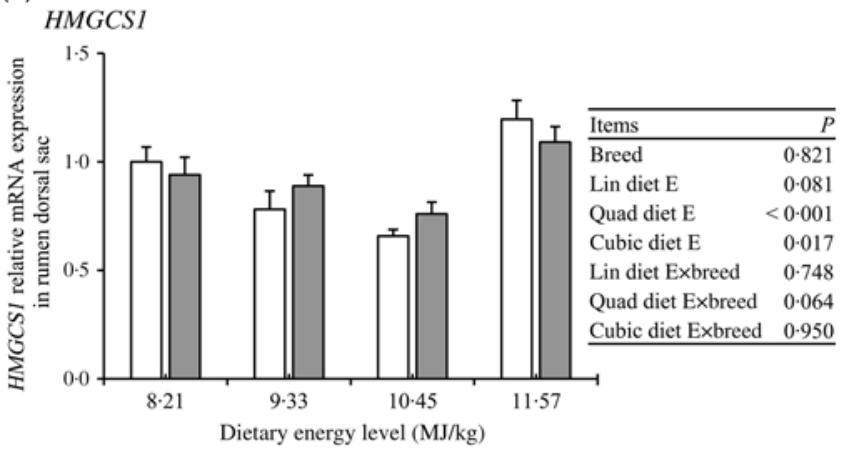

(d)

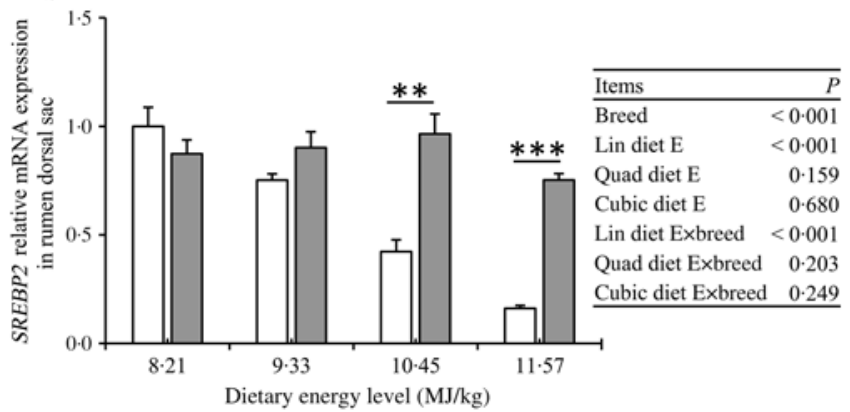

Fig. 11. Expression of acetoacetyl-CoA acetyl transferase isoform 2 (ACAT2), 3-hydroxy, 3-methylglutaryl CoA synthase isoform 1 (HMGCS1), 3-hydroxy, 3-methylglutaryl CoA reductase (HMGCR) and sterol regulatory element-binding protein 2 (SREBP-2) mRNA in the rumen dorsal sac epithelium of Tibetan (T) and small-tailed Han $(H)$ sheep offered diets of different energy $(E)$ levels. The dietary energy levels are digestible energy on a DM basis. ${ }^{* *} P<0.01,{ }^{* * *} P<0.001$. $\square$, Small-tailed Han sheep; $\square$, Tibetan sheep. Lin, linear; Quad, quadratic.

(a)

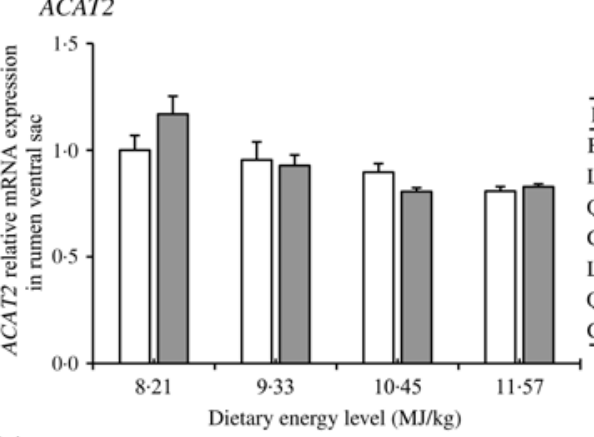

(c) $H M G C R$
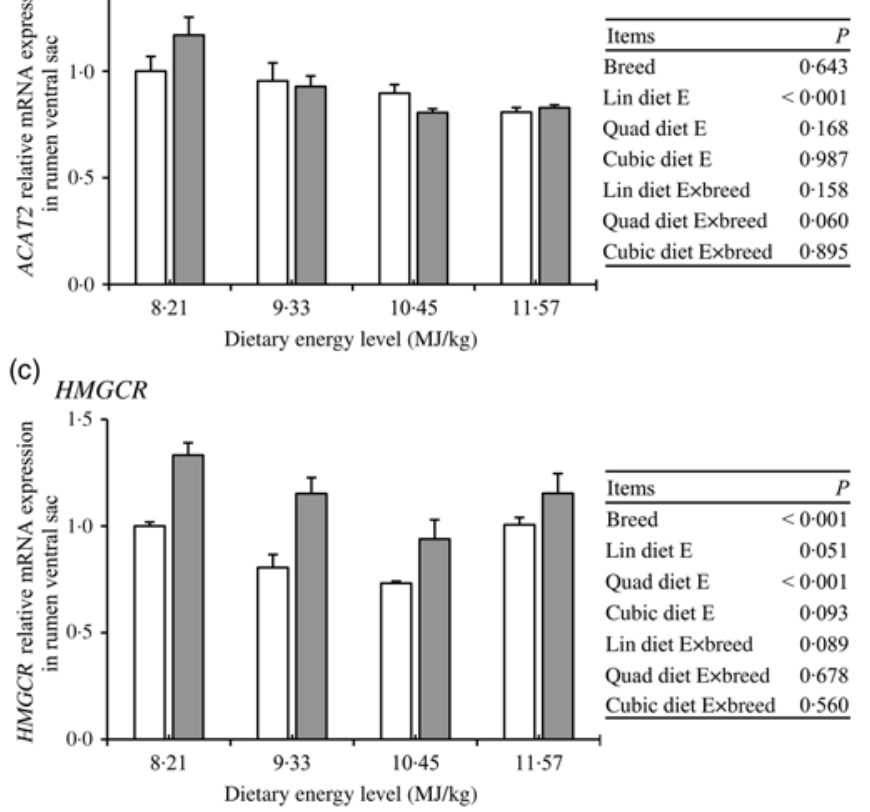

(b)

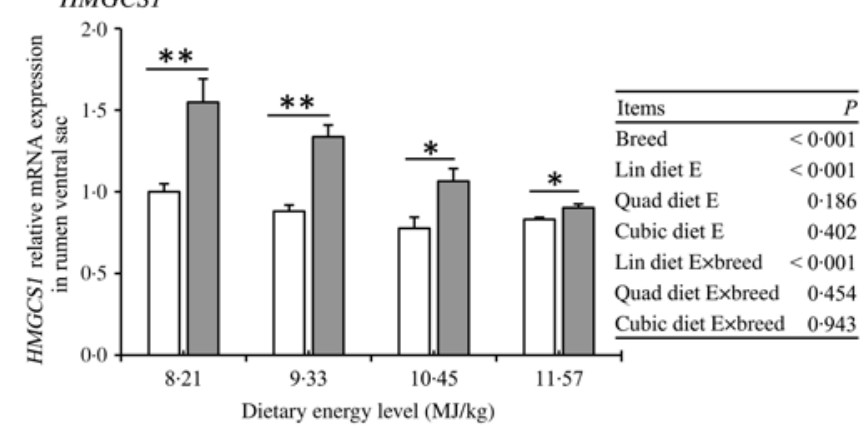

(d) $S R E B P 2$

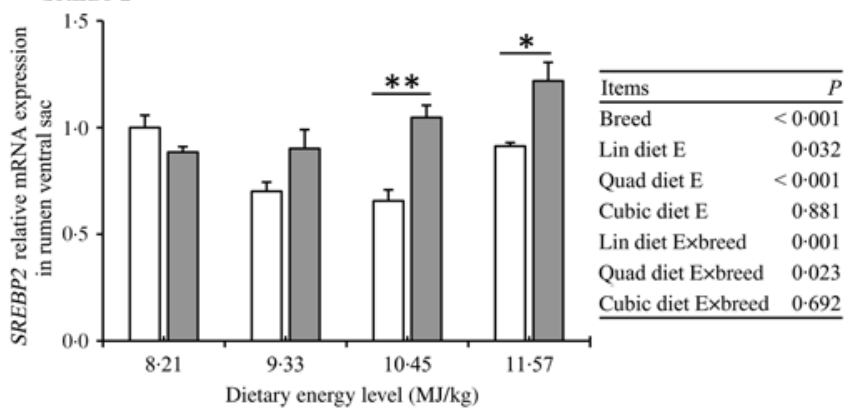

Fig. 12. Expression of acetoacetyl-CoA acetyl transferase isoform 2 (ACAT2), 3-hydroxy, 3-methylglutaryl CoA synthase isoform 1 (HMGCS1), 3-hydroxy, 3-methylglutaryl CoA reductase (HMGCR) and sterol regulatory element-binding protein 2 (SREBP-2) mRNA in the rumen ventral sac epithelium of Tibetan (T) and small-tailed Han $(\mathrm{H})$ sheep offered diets of different energy (E) levels. The dietary energy levels are digestible energy on a DM basis. ${ }^{\star} P<0.05,{ }^{\star \star} P<0.01$. $\square$, Small-tailed Han sheep; $\square$, Tibetan sheep. Lin, linear; Quad, quadratic. 
with the highly fermentable diets ${ }^{(31)}$, and the lamina propria thickness increased with a grain-based concentrate when compared with a forage-based diet ${ }^{(32)}$. However, in the present study, the thickness of the lamina propria of ruminal papillae decreased in the dorsal sac as the dietary energy level increased, which is in contrast with these reports, and was thicker in smalltailed Han than in Tibetan sheep. We reasoned the decreased lamina propria thickness with an increase in energy level was a result of the level of rumen fill and the level of contact between the ruminal epithelium and the fermentation products. Rumen fill was related to DM intake, diet composition and the rate of passage $^{(33,34)}$. With increase in dietary energy with the same DM intake in the present study, the degree of filling of the rumen decreased. Thus, the decreased lamina propria thickness with an increase in energy level in the present study was likely a result of reduced rumen fill and contact between ruminal epithelium and fermentation products.

\section{Effect of dietary energy level on ruminal epithelium SCFA} absorption relative gene $m R N A$ expression

The absorption rate of SCFA is influenced primarily by the papillae surface area and by the availability of transport proteins. Change of epithelial cell function may be the initial response to alterations in the rumen internal environment, for example, responses of the transporter activity level and the molecular state at the mRNA and protein expression levels ${ }^{(11)}$. The SCFA are absorbed in the protonated form via simple diffusion and the anionic form via carrier-mediated transport ${ }^{(5,35)}$. It was reported that most SCFA were absorbed in the anionic form $\left(\mathrm{SCFA}^{-}\right)$via carrier-mediated transport proteins, as $90-99 \%$ of the SCFA in the gastrointestinal tract were anions rather than free acids ${ }^{(6)}$. The main pathway for apical non-diffusional absorption of $\mathrm{SCFA}^{-}$has been identified via the $\mathrm{SCFA}^{-} / \mathrm{HCO}_{3}{ }^{-}$exchange, especially for acetate, and utilise $\mathrm{HCO}_{3}{ }^{-}$-dependent uptake for absorption $^{(35)}$. DRA, PAT1, AE2 and NCB1 are the key transporters involved in this pathway, with $D R A$ as the dominant expressed $\mathrm{SCFA}^{-} / \mathrm{HCO}_{3}{ }^{-}$exchanger at the mRNA level and, consequently, has a prominent role in SCFA absorption ${ }^{(5,11,35)}$. In the present study, the mRNA expression of $D R A$ was consistent with the SCFA concentrations, as it was reported that SCFA play an important role in mRNA abundance changes involved in SCFA transporters in the rumen ${ }^{(36)}$. Most of the mixing of ruminal contents occurs in the rumen mat in the ventral sac ${ }^{(37)}$; hence, most of the fermentation products should also be produced there. The mRNA expression of NCB1, PAT1 and AE2 increased linearly in the ventral sac as the dietary energy level increased, which was a result of the increased SCFA production. However, the expression of the same genes decreased in the rumen dorsal sac, which we reasoned was also due to the decreased filling and level of contact between the ruminal epithelium and the fermentation products in the dorsal sac with an increase in dietary energy level. Therefore, at the lower dietary energy level, the ruminal epithelium of the dorsal sac had a higher level of contact with the fermentation products, which induced the higher mRNA expression of the transporter. The higher mRNA expression in both the dorsal and ventral sacs in the Tibetan than in the small-tailed Han sheep conferred an advantage for the Tibetan sheep in absorbing SCFA. In addition, the higher free fatty acid receptor mRNA expression in Tibetan than in small-tailed Han sheep supported the higher absorption capability of SCFA in Tibetan sheep (online Supplementary Fig. S4). The basolateral efflux of SCFA and their metabolites are mediated primarily by the MCT ${ }^{(5,38,39)}$. In the present study, the mRNA expression of MCT1, MCT2 and MCT4 in both the dorsal and ventral sacs of the rumen exhibited a pattern similar to that of the transporter mRNA expression involved in the $\mathrm{SCFA}^{-} / \mathrm{HCO}_{3}{ }^{-}$exchange pathway. In addition, the higher expression in Tibetan than in smalltailed Han sheep at the lowest dietary energy level provided the Tibetan sheep with a higher absorption capability of SCFA, especially at the low energy intake.

Intracellular dissociation of HSCFA and the $\mathrm{HCO}_{3}{ }^{-}$export from cells in exchange for $\mathrm{SCFA}^{-}$decrease intracellular $\mathrm{pH}$. To regulate and maintain homeostasis in intracellular $\mathrm{Na}^{+}$and $\mathrm{pH}$ in rumen epithelial cells, an up-regulation of the $\mathrm{Na}^{+} / \mathrm{H}^{+}$ exchangers occurs ${ }^{(5)}$. In the present study, the NHE1 mRNA expression pattern was similar to the transporter mRNA expression in both $\mathrm{SCFA}^{-} / \mathrm{HCO}_{3}{ }^{-}$exchange and MCT pathways. The NHE3 mRNA expression was reported to be correlated positively with ruminal SCFA concentration, but negatively with ruminal $\mathrm{pH}^{(9)}$, which were in agreement with our results. The Tibetan sheep showed a higher expression than the small-tailed Han sheep at the lowest dietary energy level, which indicated a better regulating capability at low energy intakes. The $\mathrm{Na}^{+} / \mathrm{K}^{+}$-ATPase is required for full activity of NHE in the regulation of intracellular $\mathrm{pH}$, while the $\nu H^{+}$-ATPase is a complementary mechanism that contributes to approximately $30 \%$ of $\mathrm{H}^{+}$removal for the maintenance of intracellular $\mathrm{pH}$ in the absence of $\mathrm{HCO}_{3}{ }^{-(40)}$. In the present study, the mRNA expression of $\mathrm{Na}^{+} / \mathrm{K}^{+}$-ATPase and $\nu H^{+}$-ATPase was consistent with the pattern of most transporter expressions. However, small-tailed Han sheep were more dependent on $\mathrm{Na}^{+} / \mathrm{K}^{+}$-ATPase, but Tibetan sheep were more dependent on $\nu H^{+}$-ATPase, particularly at the low energy intake.

\section{Effect of dietary energy level on ruminal SCFA metabolism and metabolism regulation relative gene mRNA expression}

The ruminal epithelium, which is the greatest consumer of energy of the viscera ${ }^{(41)}$, prefers $\mathrm{SCFA}^{(7)}$. Large amounts of SCFA are metabolised by the ruminal epithelium during the process of absorption and transport to the blood stream, where butyrate is the preferred substrate ${ }^{(6,42)}$. In addition, the intra-epithelial metabolism of SCFA, particularly butyrate, helps to maintain the concentration gradient between the cytosol and lumen, thereby facilitating absorption ${ }^{(11)}$. This relationship demonstrates the interdependence of epithelial absorption and transport with that of metabolism. The dominant pathway of butyrate metabolism in the ruminal epithelium is ketogenesis, and ACAT and HMGCS are the essential enzymes for ketogenesis with 3-methylgutaryl CoA (HMG-CoA) as the central metabolite ${ }^{(43,44)}$. The isoform of ACAT1 and HMGCS2 was reported to be highly correlated with ruminal ketogenesis, and it was speculated that up-regulation of $A C A T$ may be an indicator for increased metabolism of SCFA ${ }^{(43,45)}$. Therefore, in the present study, the higher mRNA expression of ACAT1 and HMGCS2 in small-tailed 
Han sheep suggests a higher SCFA metabolism in both the dorsal and ventral sacs when compared with Tibetan sheep, which was consistent with the higher maintenance energy requirements in small-tailed Han than Tibetan sheep ${ }^{(13)}$. The promoter region of HMGCS 2 gene contains a peroxisome proliferator response element that is under the transcriptional regulation of $P P A R-\alpha$, and therefore, the metabolism of SCFA can be regulated through $P P A R-\alpha^{(46)}$. Hence, the higher PPAR- $\alpha$ mRNA expression in Tibetan sheep suggests a better regulation capacity in SCFA metabolism than in small-tailed Han sheep.

Besides the ketogenesis pathway, HMG-CoA may also proceed to the cholesterol biosynthesis pathway in the cytoplasm and $H M G C R$ is the rate-limiting enzyme of cholesterol biosynthesis ${ }^{(47,48)}$. Furthermore, ACAT2 and HMGCS1 are the key enzymatic control points in the pathway of cholesterol biosynthesis ${ }^{(11,47)}$. In the present study, the higher ACAT2, HMGCS1 and HMGCR expressions in Tibetan sheep revealed that HMG-CoA proceeds to the cholesterol biosynthesis pathway in Tibetan sheep at a faster rate than in small-tailed Han sheep. It was speculated that the down-regulation of the cholesterol biosynthesis pathway could be the long-term ruminal epithelial adaptation to highly fermentable diets ${ }^{(11)}$. Consequently, the lower expression in the cholesterol biosynthesis pathway in small-tailed Han sheep suggests that it could be related to the highly fermentable diets offered to this breed raised in feedlots under intensive management. In addition, it was reported that the cholesterol biosynthesis pathway was activated and regulated preferentially by $S R E B P 2^{(47)}$, and as $S R E B P 2$ expression was higher in Tibetan sheep, a greater regulation capacity was indicated in Tibetan than in small-tailed Han sheep.

\section{Conclusions}

Tibetan sheep produced higher yields of total SCFA than smalltailed Han sheep, especially in acetate, butyrate and iso-acids production, with the same DM intake. In addition, Tibetan sheep had greater capability to absorb SCFA as they had greater absorption surface area and higher expression of SCFA absorption relative genes in the rumen than small-tailed Han sheep. For metabolism of SCFA in the rumen epithelium, Tibetan sheep exhibited lower utilisation of the ketogenesis pathway and also better capacity to regulate SCFA metabolism pathways than small-tailed Han sheep. These differences between breeds conferred an advantage of Tibetan sheep over small-tailed Han sheep in coping with low energy intakes.

\section{Acknowledgements}

The authors would like to thank the editors and reviewers for very helpful suggestions on the manuscript. Chao Yang, Fuyu Shi, Na Guo, Qi Yan, Mingjie Hou, Jiaojiao Zhang, Weixing $\mathrm{Xu}$ and Sisi Bi helped in collecting samples.

This work was funded by the National Nature Science Foundation of China (31601960 and 31672453), a grant from State Key Laboratory of Grassland Agro-Ecosystems (Lanzhou University) and Key Research, Development and Conversion Program of Qinghai Province, China (2018-SF-145). X. J. is supported by the Chinese Scholarship Council (CSC, China).
R. L., J. Z. and X. J. conceived and designed the experiment. J. Z., X. J., W. W., Y. G., J. K. and P. L. performed the experiment. X. J., A. D., L. D. and Z. S. contributed to the writing and revising of the manuscript. All authors read and approved the final manuscript.

There are no conflicts of interest.

\section{Supplementary material}

For supplementary material referred to in this article, please visit https://doi.org/10.1017/S0007114519003222

\section{References}

1. Miller DJ (1999) Nomads of the Tibetan Plateau rangelands in Western China. Part Two. Pastoral production practices. Rangelands 21, 16-19.

2. Long R, Apori S, Castro F, et al. (1999) Feed value of native forages of the Tibetan Plateau of China. Anim Feed Sci Technol $\mathbf{8 0}$, 101-113.

3. Ding K, Shi H, Zhang Y, et al. (2011) Cold season supplementary feeding experiment of Gannan Tibetan sheep in cold grazing region. Anim Sci Vet Med 6, 28-30.

4. Zhang Z, Xu D, Wang L, et al. (2016) Convergent evolution of rumen microbiomes in high-altitude mammals. Curr Biol 26, 1873-1879.

5. Aschenbach J, Penner G, Stumpff F, et al. (2011) Ruminant nutrition symposium: role of fermentation acid absorption in the regulation of ruminal pH. J Anim Sci 89, 1092-1107.

6. Bergman E (1990) Energy contributions of volatile fatty acids from the gastrointestinal tract in various species. Physiol Rev 70, 567-590.

7. Baldwin R \& Jesse B (1992) Developmental changes in glucose and butyrate metabolism by isolated sheep ruminal cells. J Nutr 122, 1149-1153.

8. Melo L, Costa S, Lopes F, et al. (2013) Rumen morphometrics and the effect of digesta $\mathrm{pH}$ and volume on volatile fatty acid absorption. J Anim Sci 91, 1775-1783.

9. Yang W, Shen Z \& Martens H (2012) An energy-rich diet enhances expression of $\mathrm{Na}^{+} / \mathrm{H}^{+}$exchanger isoform 1 and 3 messenger RNA in rumen epithelium of goat. J Anim Sci $\mathbf{9 0}, 307-317$.

10. Shen Z, Seyfert H-M, Löhrke B, et al. (2004) An energy-rich diet causes rumen papillae proliferation associated with more IGF type 1 receptors and increased plasma IGF-1 concentrations in young goats. $J$ Nutr 134, 11-17.

11. Penner G, Steele M, Aschenbach J, et al. (2011) Ruminant Nutrition Symposium: molecular adaptation of ruminal epithelia to highly fermentable diets. J Anim Sci 89, 1108-1119.

12. Miao X \& Luo Q (2013) Genome-wide transcriptome analysis between small-tail Han sheep and the Surabaya fur sheep using high-throughput RNA sequencing. Reproduction 145, 587-596.

13. Jing X, Zhou J, Wang W, et al. (2019) Tibetan sheep are better able to cope with low energy intake than small-tailed Han sheep due to lower maintenance energy requirements and higher nutrient digestibilities. Anim Feed Sci Technol 254, 11420 .

14. Xie AY, Chai ST, Wang WB, et al. (1996) The herbage yield and the nutrient variation in mountain meadow. Qinghai J Anim Sci Vet Med 26, 8-10.

15. Metzler-Zebeli B, Hollmann M, Sabitzer S, et al. (2013) Epithelial response to high-grain diets involves alteration in nutrient transporters and $\mathrm{Na}^{+} / \mathrm{K}^{+}$-ATPase mRNA expression in rumen and colon of goats. J Anim Sci 91, 4256-4266. 
16. Hristov AN, Ivan M, Rode L, et al. (2001) Fermentation characteristics and ruminal ciliate protozoal populations in cattle fed medium- or high-concentrate barley-based diets. J Anim Sci 79, 515-524.

17. Prophet EB (1992) Laboratory Methods in Histotechnology. Washington, DC: Amer Registry of Pathology.

18. Diaz TG, Branco AF, Jacovaci FA, et al. (2018) Inclusion of live yeast and mannan-oligosaccharides in high grain-based diets for sheep: ruminal parameters, inflammatory response and rumen morphology. PLOS ONE 13, e0193313.

19. Livak KJ \& Schmittgen TD (2001) Analysis of relative gene expression data using real-time quantitative PCR and the $2^{-\Delta \Delta C T}$ method. Methods 25, 402-408.

20. Sun J, Wang F, Li H et al. (2015) Neuroprotective effect of sodium butyrate against cerebral ischemia/reperfusion injury in mice. BioMed Res Int 2015, 395895.

21. Zhou J, Guo Y, Kang J et al. (2019) Tibetan sheep require less energy intake than small-tailed Han sheep for $\mathrm{N}$ balance when offered a low protein diet. Anim Feed Sci Technol 248, 85-94.

22. Van Soest P (1994) Nutritional Ecology of the Ruminant, 2nd ed. New York: Cornell University Press.

23. Yang C-M (2002) Response of forage fiber degradation by ruminal microorganisms to branched-chain volatile fatty acids, amino acids, and dipeptides. J Dairy Sci 85, 1183-1190.

24. Miura H, Horiguchi M \& Matsumoto T (1980) Nutritional interdependence among rumen bacteria, Bacteroides amylophilus, Megasphaera elsdenii, and Ruminococcus albus. Appl Environ Microbiol 40, 294-300.

25. Bryant MP (1973) Nutritional requirements of the predominant rumen cellulolytic bacteria. Fed Proc 32, 1809-1813.

26. Dieho K, Bannink A, Geurts I, et al. (2016) Morphological adaptation of rumen papillae during the dry period and early lactation as affected by rate of increase of concentrate allowance. J Dairy Sci 99, 2339-2352.

27. Stobo IJ, Roy JH \& Gaston HJ (1966) Rumen development in the calf. 1. The effect of diets containing different proportions of concentrates to hay on rumen development. Br J Nutr 20, 171-188.

28. Mentschel J, Leiser R, Mülling C, et al. (2001) Butyric acid stimulates rumen mucosa development in the calf mainly by a reduction of apoptosis. Arch Anim Nutr 55, 85-102.

29. Steele MA, Croom J, Kahler M, et al. (2011) Bovine rumen epithelium undergoes rapid structural adaptations during grain-induced subacute ruminal acidosis. Am J Physiol Regul Integr Comp Physiol 300, R1515-R1523.

30. Hinders R \& Owen F (1965) Relation of ruminal parakeratosis development to volatile fatty acid absorption. J Dairy Sci $\mathbf{4 8}$, 1069-1073.

31. Kay M, Fell B \& Boyne R (1969) The relationship between the acidity of the rumen contents and rumenitis, in calves fed on barley. Res Vet Sci 10, 181-189.

32. Bodas R, Posado R, Bartolomé DJ, et al. (2014) Ruminal pH and temperature, papilla characteristics, and animal performance of fattening calves fed concentrate or maize silage-based diets. Chil J Agr Res 74, 280-285.
33. Aitchison E, Gill M, Dhanoa M, et al. (1986) The effect of digestibility and forage species on the removal of digesta from the rumen and the voluntary intake of hay by sheep. Br J Nutr 56, 463-476.

34. Llamas-Lamas G \& Combs D (1991) Effect of forage to concentrate ratio and intake level on utilization of early vegetative alfalfa silage by dairy cows. J Dairy Sci 74, 526-536.

35. Aschenbach R Jr, Bilk S, Tadesse G, et al. (2009) Bicarbonatedependent and bicarbonate-independent mechanisms contribute to nondiffusive uptake of acetate in the ruminal epithelium of sheep. Am I Physiol Gastrointest Liver Physiol 296, G1098-G1107.

36. Yan L, Zhang B \& Shen Z (2014) Dietary modulation of the expression of genes involved in short-chain fatty acid absorption in the rumen epithelium is related to short-chain fatty acid concentration and $\mathrm{pH}$ in the rumen of goats. J Dairy Sci $\mathbf{9 7}$, $5668-5675$.

37. Duffield T, Plaizier J, Fairfield A, et al. (2004) Comparison of techniques for measurement of rumen $\mathrm{pH}$ in lactating dairy cows. J Dairy Sci 87, 59-66.

38. Muller F, Huber K, Pfannkuche H, et al. (2002) Transport of ketone bodies and lactate in the sheep ruminal epithelium by monocarboxylate transporter 1. Am J Physiol Gastrointest Liver Physiol 283, G1139-G1146.

39. Kirat D, Masuoka J, Hayashi H, et al. (2006) Monocarboxylate transporter 1 (MCT1) plays a direct role in short-chain fatty acids absorption in caprine rumen. J Physiol 576, 635-647.

40. Albrecht E, Kolisek M, Viergutz T, et al. (2008) Molecular identification, immunolocalization, and functional activity of a vacuolar-type $\mathrm{H}^{+}$-ATPase in bovine rumen epithelium. J Comp Physiol B 178, 285-295.

41. Britton R \& Krehbiel C (1993) Nutrient metabolism by gut tissues 1. J Dairy Sci 76, 2125-2131.

42. Kristensen NB \& Harmon D (2004) Splanchnic metabolism of volatile fatty acids absorbed from the washed reticulorumen of steers. J Anim Sci 82, 2033-2042.

43. Lane M, Baldwin R IV \& Jesse B (2002) Developmental changes in ketogenic enzyme gene expression during sheep rumen development. J Anim Sci 80, 1538-1544.

44. Baldwin RL VI (1998) Use of isolated ruminal epithelial cells in the study of rumen metabolism. J Nutr 128, 293S-296S.

45. Connor E, Li R, Baldwin R, et al. (2010) Gene expression in the digestive tissues of ruminants and their relationships with feeding and digestive processes. Animal 4, 993-1007.

46. Kinoshita M, Suzuki Y \& Saito Y (2002) Butyrate reduces colonic paracellular permeability by enhancing PPAR $\gamma$ activation. Biochem Biophys Res Commun 293, 827-831.

47. Dempsey ME (1974) Regulation of steroid biosynthesis. Annu Rev Biochem 43, 967-990.

48. Steele MA, Vandervoort G, AlZahal O, et al. (2011) Rumen epithelial adaptation to high-grain diets involves the coordinated regulation of genes involved in cholesterol homeostasis. Physiol Genomics 43, 308-316. 